\title{
Uveal melanoma: physiopathology and new in situ-specific therapies
}

\author{
E. B. Souto ${ }^{1,2}$ (1) A. Zielinska ${ }^{1} \cdot$ M. Luis ${ }^{1} \cdot$ C. Carbone ${ }^{1,3} \cdot$ C. Martins-Gomes $^{4,5} \cdot$ S. B. Souto ${ }^{6} \cdot$ A. M. Silva $a^{4,5}$
}

Received: 20 December 2018 / Accepted: 2 May 2019 / Published online: 11 May 2019

(c) Springer-Verlag GmbH Germany, part of Springer Nature 2019

\begin{abstract}
Uveal melanoma is the most common primary intraocular tumor in adults. It can arise from melanocytes in the anterior (iris) or posterior uveal tract (choroid and ciliary body). Uveal melanoma has a particular molecular pathogenesis, being characterized by specific chromosome alterations and gene mutations (e.g., GNAQ/GNA11; BAPI), which are considered promising targets for molecular therapy. Primary treatment of uveal melanoma includes radiotherapy (brachytherapy and charged-particle therapy), phototherapy (photocoagulation, transpupillary thermal therapy, and photodynamic therapy) and surgery (local resection, enucleation and exenteration). Approximately half of patients with uveal melanoma will, however, develop metastasis, especially in the liver. The treatment of metastatic uveal melanoma includes systemic chemotherapy, immunotherapy and molecular targeted therapy. Liver-directed therapies, such as resection, chemoembolization, immunoembolization, radioembolization, isolated hepatic perfusion and percutaneous hepatic perfusion, are also available to treat metastatic uveal melanoma. Several clinical trials are being developed to study new therapeutic options to treat uveal melanoma, mainly for those with identified liver metastases. The present work discusses the physiopathology and new in situ-specific therapies for the treatment of uveal melanoma.
\end{abstract}

Keywords Uveal melanoma $\cdot$ Photocoagulation · Transpupillary thermal therapy $\cdot$ Photodynamic therapy $\cdot$ Liver metastases $\cdot$ Liver-directed therapies

\section{Abbreviations}

$\alpha$-MSH $\quad \alpha$-Melanocyte-stimulating hormone

AJCC American Joint Committee on Cancer

BAP1

$B R C A 1$-associated protein

BCUN 1,3-Bis(2-chloroethyl)-1-nitrosourea

E. B. Souto

ebsouto@ebsouto.pt

1 Department of Pharmaceutical Technology, Faculty of Pharmacy, University of Coimbra (FFUC), Pólo das Ciências da Saúde, Azinhaga de Santa Comba, 3000-548 Coimbra, Portugal

2 CEB-Centre of Biological Engineering, University of Minho, Campus de Gualtar, 4710-057 Braga, Portugal

3 Laboratory of Drug Delivery Technology, Department of Drug Sciences, University of Catania, Catania, Italy

4 Department of Biology and Environment, University of Trás-os-Montes e Alto Douro, UTAD, Quinta de Prados, 5001-801 Vila Real, Portugal

5 Centre for Research and Technology of Agro-Environmental and Biological Sciences, CITAB, UTAD, Quinta de Prados, 5001-801 Vila Real, Portugal

6 Department of Endocrinology and Metabolism, Hospital of Braga, Sete Fontes, São Victor, 4710-243 Braga, Portugal

$\begin{array}{ll}\text { CGH } & \text { Comparative genomic hybridization } \\ { }^{60} \text { Co } & \text { Cobalt-60 } \\ \text { COMS } & \text { Collaborative Ocular Melanoma Study } \\ \text { CRNDE } & \text { Colorectal neoplasia differentially } \\ & \text { expressed } \\ \text { CRPs } & \text { Complement regulatory proteins } \\ \text { CT } & \text { Computed tomography } \\ \text { CTLA-4 } & \text { Cytotoxic T-lymphocyte-associated } \\ \text { CYSLTR2 } & \text { protein-4 } \\ \text { EIF1AX 1A } & \text { Eusteinyl leukotriene receptor 2 } \\ \text { FDA } & \text { Food and Drug Administration } \\ \text { FDG-PET/CT } & \text { Fluoro-2-deoxy-D-glucose positron } \\ \text { FISH } & \text { emission/CT } \\ \text { GEP } & \text { Fluorescence in situ hybridization } \\ \text { GM-CSF } & \text { Gene expression profiling } \\ \text { GNA11 } & \text { Granulocyte-macrophage colony-stimu- } \\ & \text { lating factor } \\ \text { GNAQ } & \text { Guanine nucleotide-binding protein subu- } \\ \text { HDACis } & \text { nit alpha-11 } \\ \text { Guanine nucleotide-binding protein G(q) }\end{array}$




\begin{tabular}{|c|c|c|}
\hline HGF & Hepatocyte growth factor & Vasoactive intestinal peptide \\
\hline${ }^{125} \mathrm{I}$ & Iodine- 125 & Yes-activated protein \\
\hline IFN- $\gamma$ & Interferon- $\gamma$ & \\
\hline IGF-1 & Insulin-like growth factor- 1 & \\
\hline IGF-1R & IGF-1 receptor & Introduction \\
\hline IHP & Isolated hepatic perfusion & \\
\hline lncRNA & Long non-coding RNA & Ocular melanoma is a rare type of melanoma, representing \\
\hline MAPK & Mitogen-activated protein kinase & $3-5 \%$ of all melanoma cases, developed from melanocytes \\
\hline MHC & Major histocompatibility complex & anywhere within the eye, including the uveal tract, conjunc- \\
\hline MLPA & $\begin{array}{l}\text { Multiplex ligation-dependent probe } \\
\text { amplification }\end{array}$ & $\begin{array}{l}\text { tiva and orbit [1]. Uveal melanoma, which is the most com- } \\
\text { mon primary intraocular tumor in adults, can arise both in }\end{array}$ \\
\hline MRI & Magnetic resonance imaging & the anterior (iris) and posterior uveal tracts (choroid and \\
\hline MSA & Microsatellite analysis & ciliary body) [2, 3] (Fig. 1). Despite advances in the under- \\
\hline MUM & Metastatic uveal melanoma & standing of the disease and new therapeutic options, the inci- \\
\hline PBT & Proton beam therapy & dence of uveal melanoma has remained unchanged. Uveal \\
\hline${ }^{103} \mathrm{Pd}$ & Palladium-103 & melanoma has a particular molecular pathogenesis, being \\
\hline PD-L1 & Programmed death ligand-1 & characterized by specific chromosome alterations and gene \\
\hline PDT & Photodynamic therapy & mutations, representing, therefore, appropriate targets for \\
\hline PFS & Progression-free survival & molecular therapy. These cytogenetic features are important \\
\hline PI3K & Phosphatidylinositol 3-kinase & in the diagnosis and prognosis of the disease. About $47 \%$ of \\
\hline PKC & Protein kinase $\mathrm{C}$ & patients with primary uveal melanoma present mutations \\
\hline PLCB4 & Phospholipase $\mathrm{C}$ beta 4 & in $B R C A 1$-associated protein $(B A P I)$. The diagnosis is usu- \\
\hline${ }^{106} \mathrm{Ru}$ & Ruthenium-106 & ally made by ophthalmoscopy and ultrasound [4]. Fluores- \\
\hline SNPs & Single nucleotide polymorphisms & cein angiography is also a useful technique. Cross-sectional \\
\hline SF3B 1 & Splicing factor $3 b$ subunit 1 & imaging may be necessary in certain cases and this includes \\
\hline TGF- $\beta$ & Transforming growth factor $\beta$ & magnetic resonance imaging (MRI), computed tomogra- \\
\hline TTT & Transpupillary thermal therapy & phy (CT) and fluoro-2-deoxy-D-glucose positron emission/ \\
\hline UV & Ultraviolet & CT (FDG-PET/CT). Primary treatment of uveal melanoma \\
\hline VEGF & Vascular endothelial growth factor & includes radiotherapy (brachytherapy and charged-particle \\
\hline
\end{tabular}

Fig. 1 Eye anatomy and sites for uveal melanoma development (iris, choroid and ciliary body)

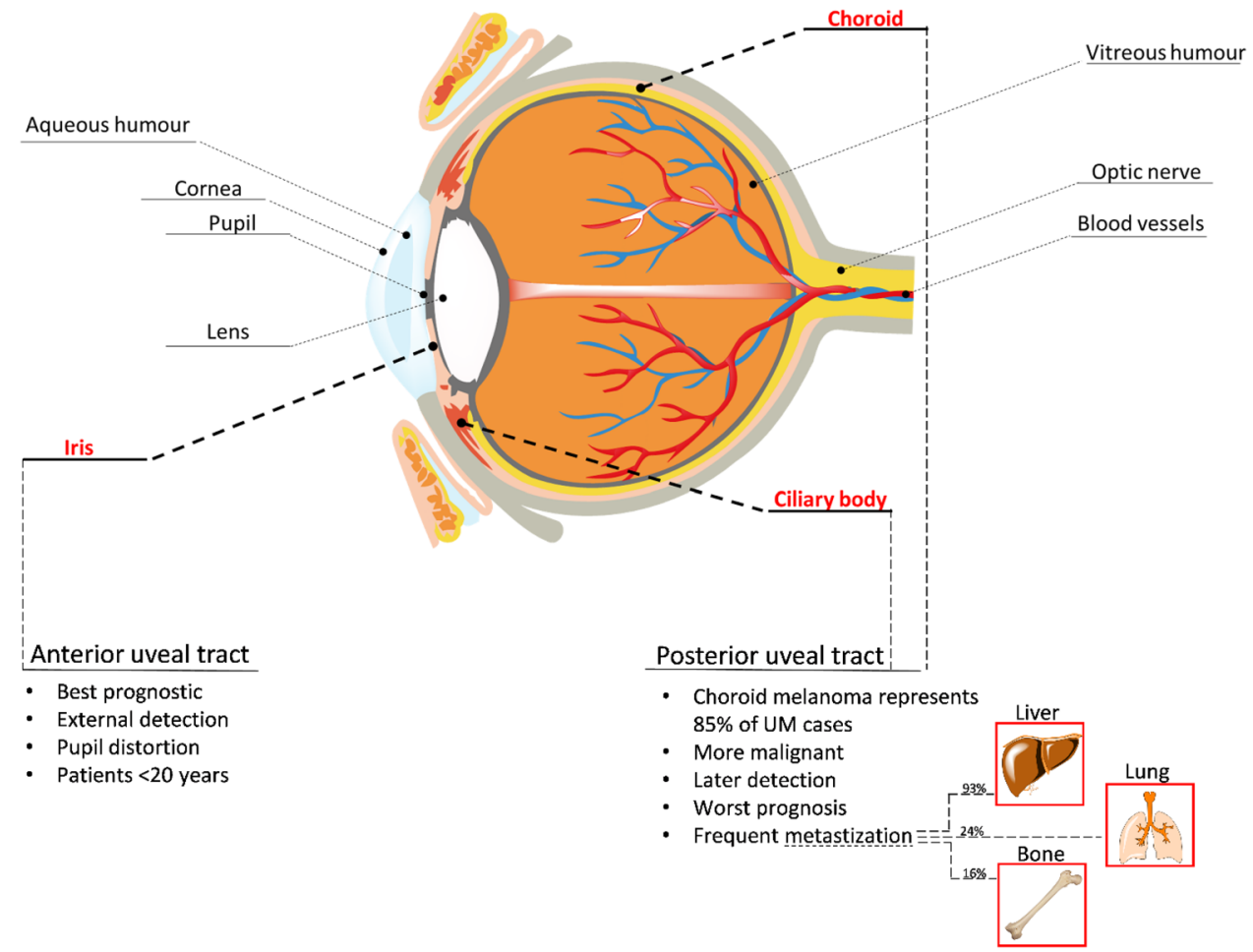


therapy), phototherapy (photocoagulation, transpupillary thermal therapy, and photodynamic therapy) and surgery (local resection, enucleation and exenteration) [5, 6]. All these techniques have shown a reasonable local control of the tumor. Since the results of the Collaborative Ocular Melanoma Study (COMS) study suggested no difference in mortality for patients with medium-sized melanomas treated either with brachytherapy or enucleation, eye-conserving therapies have been used in the majority of patients. Nevertheless, approximately half of patients with primary uveal melanoma will develop metastases, especially in the liver [1]. The treatment of metastatic uveal melanoma includes systemic chemotherapy, immunotherapy and molecular targeted therapy [5]. Response rates of metastatic uveal melanoma to systemic chemotherapy are poor and overall survival is questionable. Liver-directed therapies are also used to control metastatic uveal melanoma, with reported higher response rates and median survival. However, the apparent improvement in the overall survival with liverdirected therapies is due to patient selection bias [7]. Alternative treatments include resection, chemoembolization, immunoembolization, radioembolization, isolated hepatic perfusion (IHP) and percutaneous hepatic perfusion (PHP).

\section{Eye anatomy and physiology}

The human eye measures approximately $25 \mathrm{~mm}$ and is a sensory organ responsible for the sense of sight [8]. The eye is composed of three main parts: eyeball, orbit and accessory (adnexal) structures $[8,9]$. The eyeball is also called the globe and is rich in blood vessels. Its interior is filled with vitreous humor which fills the posterior part of the eye and helps to support the internal structures and maintain the shape of the eye. The outer part of the eyeball is called the wall of the eye and can be divided into three structural layers (or tunics): outer, middle and inner layers (from the outside to the inside of the eye) [8].

The outer layer, named as the corneoscleral coat, includes the sclera and cornea [8]. The sclera is the white portion of the eye and is predominantly composed of dense connective tissue and acts as the protective covering. Blood vessels and optic nerve pass through the sclera, and muscles that control the eye movement attach to this structure. The cornea is transparent and covers the pupil and the iris and does not contain any blood vessels [9]. The corneal epithelium has an average thickness of approximately $50 \mu \mathrm{m}$ and is a nonkeratinized stratified squamous epithelium [8].

Middle layer, where intraocular melanoma forms, is also called the uvea or vascular tunic and has three main parts: iris, choroid and ciliary body [8]. Iris is the colored part of the eye and is located between the cornea and the lens [9]. The pupil is in the center of the iris and changes its size to let more or less light to enter the eye $[8,9]$. Intraocular melanoma of the iris is usually a small tumor that grows slowly and rarely spreads to other parts of the body. The choroid is a layer of blood vessels that brings oxygen and nutrients to the eye. This structure is rich in pigment-producing cells called melanocytes. Thus, the choroid is the part of the eye where most intraocular melanomas are developed, are diagnosed at a later state, and are more likely to spread to other parts of the body. Lastly, the ciliary body is a ring of tissue with muscle fibers that helps the eye focus since it changes the shape of the lens. It is located behind the iris and extends forward from the choroid. The ciliary body contains cells that produce the aqueous humor, a clear fluid that fills the space between the cornea and the iris. Intraocular melanoma of the ciliary body is larger and more likely to spread to other parts of the body than intraocular melanoma of iris. Thus, uvea is composed of endothelial cells, immune cells and melanocytes [8].

Finally, the inner layer is composed of the retina or neural tunic, which is a layer of cells at the back of eyeball $[8,9]$. It also includes nerve cells that are connected to the brain by optic nerve, which sends information from the eye to the brain and allows human beings to see. The lens, which is a transparent structure in the inner part of the eye, is responsible for focussing light rays on the retina.

The orbit is a bowl-shaped cavity made up of bone formed from the skull that contains the eyeball and the connective tissues surrounding the eyeball, which are responsible for cushioning and protecting the eye $[8,9]$. Muscles attached to the eyeball make it move in different directions. Furthermore, these small muscles attach to the sclera near the front of the eye and to the bones of the orbit at the back. The orbit also contains nerves, fat, blood vessels and a variety of connective tissues [8].

The three layers of the eye, along with the lens, function as boundaries for the three chambers within the eye $[8,9]$. They are the anterior chamber (which is the space between the cornea and the iris), the posterior chamber (which is the space between the iris and the lens), and the vitreous chamber (which is the space between the lens and the retina). The eye can be further divided into the anterior segment (which is formed by the cornea and both anterior and posterior chambers) and the posterior segment (which contains the vitreous chamber, the retina, retinal pigment epithelium, posterior sclera and the uvea). Accessory structures include the eyelids, conjunctiva, caruncle and lacrimal glands. Conjunctiva is a clear mucous membrane that lines the inner surface of the eyelids secreting mucus to lubricate the eyeball and keep it moisturized $[8,9]$. 


\section{Uveal melanoma: physiopathology}

The majority of melanomas are developed from melanocytes within the skin, but they can also arise at other sites, as may happen anywhere within the eye, including the uveal tract, conjunctiva and orbit [3]. The majority of uveal melanoma cases, approximately $85 \%$, occur in the choroid with the remaining cases arising in the ciliary body or iris. Melanomas of the posterior uveal tract are generally more malignant, detected later and metastasize more frequently than iris melanomas. Thus, melanomas of the ciliary body have the least favorable prognosis and iris melanomas the best prognosis [9].

Uveal melanomas appear as discrete masses between the thick, fibrous sclera and the retina, often pushing the retina into the vitreous space. Uveal melanoma usually remains confined to the globe, but larger tumors may develop extrascleral extension. Other pathways of extraocular spread include the optic nerve and the lumen of vortex veins [10, 11]. The highly vascular nature of uvea provides a good mean for the spread of uveal melanoma cells to distant organs through the bloodstream [12]. The lymphatic structures in the eye are rare (confined to extraocular conjunctiva and limbus) and too small for the passage of the cells, so regional spread of uveal melanoma is extremely rare. Instead, uveal melanomas metastasize by hematogenous dissemination $[10,12,13]$. The most common metastasizing sites are the liver (93\%), lungs (24\%), and bones (16\%), with the overwhelming majority initially occurring the liver [14].

Most uveal melanomas are initially asymptomatic [15]. As the tumor enlarges, it may cause distortion of the pupil (iris melanoma), blurred vision (ciliary body melanoma), or markedly decreased visual acuity induced by secondary retinal detachment (choroidal melanoma). Serous detachment of the retina can also take place and, if extensive detachment occurs, secondary angle-closure glaucoma casually develops [9].

\section{Epidemiology}

Melanoma of the uveal tract is the most widespread primary intraocular tumor in adults, with an annual incidence of six cases per million in Caucasians and 5.1 per million worldwide. This rate appears to remain stable over the time despite advances in the understanding of the disease and new therapeutic options [16]. In Europe, uveal melanoma incidence evidences the north-south gradient, decreasing from over 8 per million in northern to less than 2 per million in southern countries [17].

Most patients with uveal melanoma are aged from 50 to 80 years, having a peak in 70 s [18], and the average age at diagnosis is 58 years [19]. Iris melanoma is more frequent among young patients ( $<20$ years) and corresponds to $21 \%$ of all uveal melanoma among them, in comparison to $4 \%$ and $2 \%$ in age groups $20-60$ and $>60$, respectively [17].

Up to $50 \%$ of patients develop metastases within a median period of 2.4 years and the median survival with metastases ranges from 3 to 12 months due to the lack of effective treatment choices [20].

\section{Molecular pathology of uveal melanoma}

The molecular pathogenesis of uveal melanoma is distinct from that of cutaneous melanoma, being characterized by specific chromosome alterations and gene mutations [21, 22]. Most uveal melanomas exhibit relatively low degree of genomic instability and aneuploidy compared to many other cancer types. The most common chromosomal abnormalities include loss of $1 \mathrm{p}, 3,6 \mathrm{q}$, and $8 \mathrm{p}$ and gain of $1 \mathrm{q}$, $6 \mathrm{p}$ and $8 \mathrm{q}$. These cytogenetic features are important in the prognosis of uveal melanoma. These were initially identified by standard karyotypic analysis, but have been confirmed by fluorescence in situ hybridization (FISH) [23], comparative genomic hybridization (CGH) [24], spectral karyotyping [13], microsatellite analysis (MSA) [25], multiplex ligation-dependent probe amplification (MLPA) [26] and single nucleotide polymorphisms (SNPs [27].

Loss of copy of chromosome 3 (monosomy 3 ) occurs in nearly half of uveal melanomas, being the most prognostically meaningful chromosomal marker in uveal melanoma [25, 28-30]. Monosomy 3 is deeply associated with clinical and histopathologic prognostic factors (larger tumor diameter, ciliary body tumor location, epithelioid cell type, high mitotic rate, vascular loops, and extraocular extension) and metastatic death as well $[13,31]$. To search candidate genes on chromosome 3 and to identify specific mutations needed to establish pathogenic relevance, Harbour et al. [32] conducted a study of two uveal melanomas which were known to be monosomic to chromosome 3 and to have given rise for metastases. The authors found that $B A P 1$, located at chromosome 3 p21.1, was the only gene on chromosome 3 that was mutated in both tumors. Furthermore, they found inactivating mutations in BAP1 in 27 of 57 uveal melanomas $(47 \%)$. These mutations occurred almost exclusively in metastasizing tumors that had also lost the other copy of chromosome 3.

Uveal melanoma is genetically characterized by frequent, mutually exclusive mutations in guanine nucleotide-binding protein $\mathrm{G}(\mathrm{q})$ subunit alpha $(G N A Q)$ and guanine nucleotidebinding protein subunit alpha-11 (GNA11), two closely related large GTPases of Goq family [3, 33, 34]. These mutations take place at either arginine 183 (R 183) or glutamine 209 (Q209) and are recognized as driver mutations 
in uveal melanoma since those convert the $\mathrm{G}$ proteins into a constitutively active form by blocking intrinsic GTPase activity and, consequently, activate downstream pathways $[35,36]$. Therefore, GNAQ and GNA11 mutations lead to the activation of three pathways which are known to promote cell growth and proliferation. Those comprise mitogen-activated protein kinase (MAPK) pathway [37], phosphatidylinositol 3-kinase (PI3K)/Akt pathways [3] and Yes-activated protein (YAP) pathway [38]. These appear to be major contributors to the development of uveal melanomas [3, 39]. These three pathways are known to promote cell growth. Thus, G $\alpha$ activates phospholipase C (PLC- $\beta$ ), which leads to protein kinase $\mathrm{C}$ and $\mathrm{Raf} / \mathrm{MEK} / \mathrm{ERK}$ mitogen-activated protein kinase (MAPK) pathway activation. These mutations can also lead to YAP pathway activation through Trio-Rha/ Rac signaling circuit, which promotes the polymerization of globular actin to filamentous actin. This then binds to the cytoskeletal protein angiomotin, releasing YAP, and allowing it to enter the nucleus and initiate the transcription of genes involved in proliferation, anti-apoptosis and cell survival.

Mutations of $B R C A 1$-associated protein $B A P 1$, which is a suppressor gene, are present in about $47 \%$ of primary uveal melanoma injuries. The presence of $B A P 1$ mutations in uveal melanoma is associated with a high probability of metastases. Potential activities of BAPl include cell cycle regulation and maintenance of cell integrity [37]. BAPI is an enzyme that takes out ubiquitin molecules from particular proteins to regulate their function. Genes involved in melanocyte differentiation and function are affected by $B A P 1$ loss. Thus, loss of BAPI leads to the reversion of melanocytes to a de-differentiated, stem cell-like state which conceivably contributes to their pro-metastatic behavior [40, 41].

The $B A P 1$ gene maps to chromosome $3 \mathrm{p} 21$ and $B A P 1$ mutations that occur in uveal melanomas are followed by primarily somatic complete or partial loss of chromosome 3. Approximately $1-3 \%$ of patients with uveal melanoma are possibly to harbor a predisposing germline mutation in $B A P 1$; besides, tumor progression will also depend on loss of wild-type $B A P 1$ [37]. Although rare, BAP1 mutations are also associated with predisposition to a variety of other cancers, such as cutaneous melanoma, mesothelioma and renal cell cancer [42-44]. According to Woodman [45], $B A P 1$ mutations were strongly associated with class 2 tumor status, chromosome 3 loss in primary tumors and the final emergence of metastatic disease in the patients.

$G N A Q / 11$ mutations are not enough for full malignant conversion to melanoma [33]. This would seem to position $G N A Q / 11$ mutations as early or possibly initiating events in uveal melanoma development. Moreover, $B A P 1$ mutations are known to be almost solely metastasizing class 2 tumors with monosomy 3 , suggesting that this mutation occurs considerably late in the primary tumor and may act as a rate-limiting step in metastases. Either $B A P 1$ mutation or loss of chromosome 3 can occur first, yet both events seem to be required for the tumor to obtain the metastasizing class 2 phenotype [13].

Significant effort has been made to better elucidate the biological mechanisms of distant spread to the liver. A variety of growth factors, such hepatocyte growth factor (HGF) which is produced in the liver and its corresponding tyrosine kinase receptor c-Met, have been considered to be involved in metastatic progression of uveal melanoma. Activated c-met seems to play an important role in proliferation, survival and cell migration and appears to be highly expressed in primary uveal melanoma cells [45-47].

Another hormone greatly secreted by the liver is the insulin-like growth factor 1 (IGF-1) [47]. IGF-1 binds to its receptor, IGF-1 receptor (IGF-1R), leading to cell proliferation, survival and migration. Like c-Met, IGF-1R has been shown to be expressed in primary uveal melanoma [45, 48].

Loss of part of chromosome $1 \mathrm{p}$ occurs in around a quarter of uveal melanomas and more frequently occurs in the background of monosomy 3 [49]. Despite concomitant loss of chromosome $1 p$ and 3 exhibiting a greater correlation with melanoma-related metastases, this represents one of the few chromosomal abnormalities that are independent of chromosome 3 status, with its presence leading to reduced disease-free survival [50].

Gain of chromosome $6 p$ and loss of $6 q$ arises, equally, in close to a quarter of uveal melanomas. While $6 \mathrm{q}$ loss is associated with poor prognosis, $6 \mathrm{p}$ gain is associated with better prognosis once it tends to occur in the absence of monosomy 3 [29]. The coexistence of $6 p$ gain and monosomy 3 occurs just in $4 \%$ of cases of uveal melanoma [31]. This led some researchers to speculate about its "protective" effect against metastases [13].

Chromosome $8 \mathrm{p}$ loss occurs in about a quarter and $8 \mathrm{q}$ gain in almost $40 \%$ of uveal melanomas. $8 \mathrm{q}$ gain is statistically associated with metastases given that the smallest region of common gain on $8 \mathrm{q}$ has been narrowed to the large region 8q23-24-qter, which contains many potential oncogenes. However, no pathogenic importance has been related and no particular oncogenic mutations on $8 \mathrm{q}$ have been assessed in uveal melanoma [13]. 8q gain is a poor prognosis factor (more frequently associated with metastases) [51], mainly when it occurs in the context of $8 p$ loss, suggesting the formation of an isochromosome $8 \mathrm{q}$ [13]. This frequently occurs in tumors that have lost a copy of chromosome 3 , and it is considered an independent prognostic factor of progressive disease [52]. Gain of chromosome 8 or obtainment of an isochromosome $8 \mathrm{q}$ may be a posterior occurrence in the setting of uveal melanoma, and is verified in both low- and high-risk uveal melanomas [53]. 
Regarding uveal melanoma, it is possible, by the use of new sequencing tools, to detect the most recurrent mutated genes, which will eventually enable to predict the disease outcome. Martin et al. [54] identified recurrent somatic mutations that affect the $\mathrm{N}$ terminus of EIFIAX (eukaryotic translation initiation factor 1A) which occur exclusively in uveal melanomas with disomy 3. In Ewens et al. [55] study, patients diagnosed with uveal melanoma that evidenced a mutation in EIFIAX gene were prone to have lower risk to develop metastasis in the 48 months after uveal melanoma treatment. Similar to EIFIAX gene mutations, SF3B1 (splicing factor $3 \mathrm{~b}$ subunit 1 ) mutations are associated with a good prognosis for uveal melanoma [56]. Decatur et al. [57] detected mutations in $S F 3 B 1$ gene in $23 \%$ of the patients with uveal melanoma; this genetic finding associated with an intermediate tendency of the uveal melanoma to metastasize. The mutation in SF3B1 gene occurs in the codon R625 (which corresponds to the arginine-625 in the protein) and rarely occurs simultaneously with a $B A P 1$ mutation [58]. SF3B1 gene encodes a splicing factor, and it is known that a modification in a spliceosomal component can modify the splicing of a gene which, ultimately, affects protein structure altering its function [59]. In fact, $S F 3 B 1$ mutations in uveal melanoma are associated with alternative splicing of transcripts of UQCC gene (which encodes the ubiquinol-cytochrome c reductase complex chaperone) and $A B C C 5$ gene (multidrug resistance-associated protein 5) [58]. Additionally, $S F 3 B 1$ mutations are also associated with alternative splicing of exon 4 of $C R N D E$ (colorectal neoplasia differentially expressed), a long non-coding RNA (IncRNA).

The evolution of molecular testing has enabled the discovery of major driver mutations that allow the anticipation of the prognosis of uveal melanoma. CYSLTR2 (cysteinyl leukotriene receptor 2) and PLCB4 (phospholipase C beta 4) constitute two additional genes frequently mutated in uveal melanoma. CYSLTR2 is an oncogene that promotes uveal melanoma tumorigenesis through the activation of endogenous heterotrimeric G proteins [60]. PLCB4 is the downstream target of GNA11 and GNAQ; and mutations in GNA11 and GNAQ genes are usually associated with PLCB4 gain-of-function mutation, which leads to the activation of intracellular pathways that, ultimately, conduct to the proliferation of uveal melanoma cells [61]. Figure 2 illustrates the metabolic pathways, interaction with surrounding cells and metastasis process.

\section{Risk factors, detection and diagnosis of uveal melanoma}

Several risk factors are identified for the development of uveal melanoma. Among host [62] and environmental risk factors are the presence of related ocular or cutaneous melanocytic lesions, fair complexion and light iris [63]. Regarding sunlight exposure, the relationship between ultraviolet (UV) light exposure and uveal melanoma risk has not been

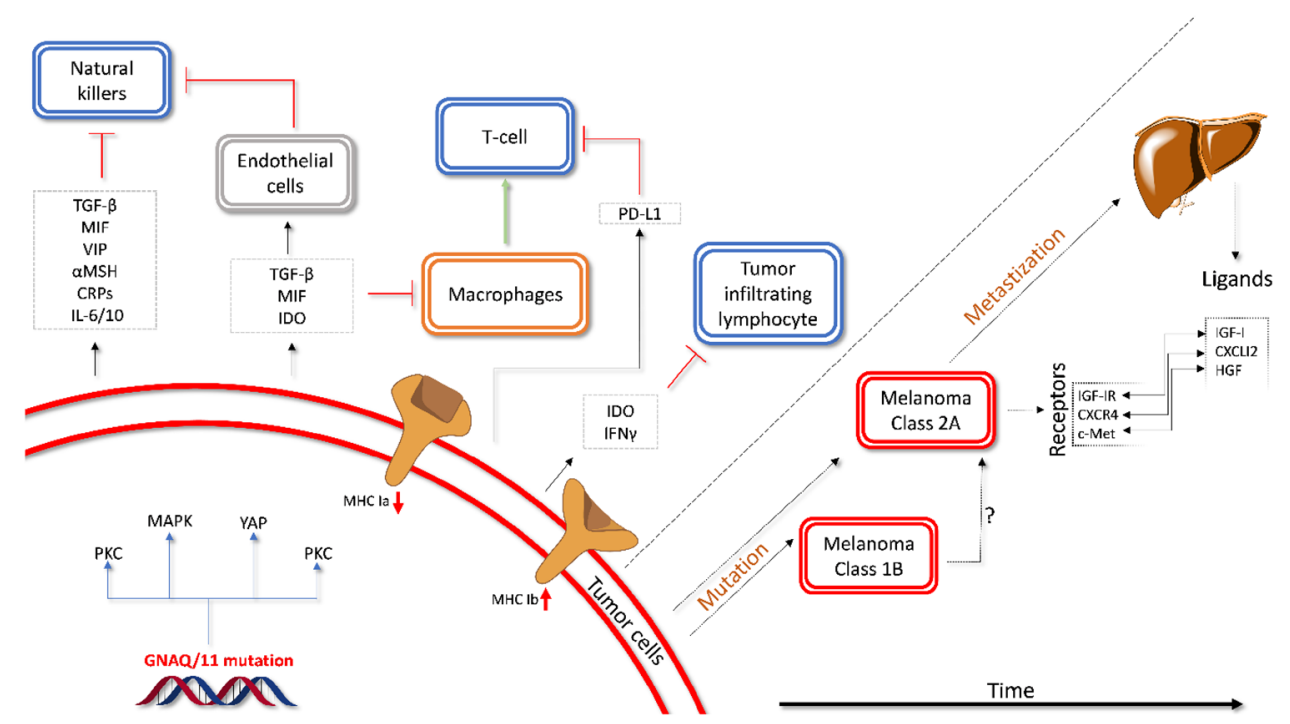

Fig. 2 Metabolic pathways, interaction with surrounding cells and metastasis process. Due to mutation in $G N A Q / 11$, molecular pathways such as MAPK, YAP, PKC and AKT are activated. Since they are upstream proteins, a response will be produced resulting in the production of immunosuppressive molecules (as TGF- $\beta$; MIF; VIP; CRPs) that directly inhibit lymphocytes, macrophages and natural killer cells, preventing the tumor cells from being destroyed by the immune system. When mutated, tumor cells may become melanoma class 1B (when cells gain chromosome $6 \mathrm{p}$ and still retain the gene expression signature of class 1) or 2A (this class is associated with chromosome 3 loss). The latter can easily form metastases, with preference to the liver, which might be due to specific ligands present in liver tissue to receptors expressed by uveal melanoma class $2 \mathrm{~A}$ cells 
clearly established. According to Shah et al. [64], chronic UV exposure, including sunlight exposure and geographic latitude, was not significantly related to uveal melanoma. In fact, regarding SF3B1 mutations, Furney et al. [58] reported no UV mutation profile in whole genome data of uveal melanomas, which argues against a relevant role for sunlight in the pathogenesis of this tumor. Mainster and Turner [65], on the other hand, concluded that UV-B radiation exposure and lack of use of sunglasses have been related to uveal melanoma risk.

The diagnosis is usually done by ophthalmoscopy and ultrasound due to the superficial position of the globe and its cystic composition. Ultrasound with Doppler enables a noninvasive and cost-effectiveness follow-up. The technique is well tolerated and easy to undertake, and evidences a high accuracy for the characterization of vascular lesions [66]. Ultrasound is a valuable tool as well for the follow-up of patients submitted to conservative treatments [10].

Fluorescein angiography is also a useful technique given that, in patients with melanoma, it causes irregular hyperfluorescence in the early phase while staging of the tumor is observed in the late phase. Furthermore, it promotes an accurate assessment and follow-up of the basal dimension of the lesion primarily and post-treatment [10].

Cross-sectional imaging may be needed in case of opaque lens or significant subretinal effusion. The appropriate imaging modality depends on the clinical presentation and patient's age. Cross-sectional imaging plays an important role in the diagnosis and management of these lesions. However, a biopsy may be needed to provide tissue diagnosis. Magnetic resonance imaging (MRI), computed tomography (CT) and fluoro-2-deoxy-D-glucose positron emission/CT (FDG-PET/CT) are equally useful imaging techniques. MRI is the imaging technique of choice, whereas CT is reserved for cases with suspected bony pathology and whenever MRI cannot be performed [66]. MRI can be used to provide intraocular enhancement of the lesion, helping to predict the degree of malignancy and for monitoring the response to treatment [10]. PET/CT is able to detect metabolic activity of choroidal melanomas. Moreover, it plays a valuable role in detecting regional and distant metastases from choroidal melanomas. However, it is unable to differentiate between small melanomas and suspicious choroidal nevus [66].

Several clinical findings are available to help to identify a melanoma, including tumor thickness of greater than $2 \mathrm{~mm}$, presence of subretinal fluid, visual symptoms, presence of orange pigment on the tumor surface, margin within $3 \mathrm{~mm}$ of the optic disc, ultrasound hollowness, halo absent and drusen absent [63]. These, however, occur only in a small percentage of cases [67], while in the majority of the situations diagnosis is made by physical examination.

Histopathological risk factors play an important role in the diagnosis of ocular melanoma and differentiating it from a nevus and include cell type, location, growth pattern, mitotic figures, pigmentation, necrosis and inflammatory components and vascularity [63]. Four distinct cellular types are recognized in intraocular melanoma: spindle-A cells (spindle-shaped cells with slender nuclei and lacking visible nucleoli), spindle-B cells (spindle-shaped cells with larger nuclei and distinct nucleoli), epithelioid cells (larger polygonal cells with one or more prominent nucleoli) and intermediate cells (similar to but smaller than epithelioid cell). Thus, intraocular melanomas can be classified into spindle cell nevus, spindle cell malignant melanoma, mixedcell melanoma, and epithelioid cell melanoma. Taking into account this classification, spindle cell tumors carry the best prognosis and epithelioid cell tumors the worst. However, epithelioid cell melanomas are infrequent and mixed-cell type melanomas predominate [63]. Regarding the location of the tumor, juxtapapillary placed and more anteriorly placed tumors are more likely to be of epithelioid cell and are also more likely to metastasize and progress. Diffuse growth pattern has been shown to be associated with a higher incidence of extraocular extensions and higher metastatic potential. Presence of mitotic figures is highly suggestive of malignancy and is a well-known risk factor for metastases. Heavy pigmentation has been found to be associated with epithelioid cell type, larger sized tumors, necrosis and the presence of macrophages (which increases risk of malignancy) [68]. A choroidal melanoma shows a more prominent vasculature which is associated with epithelioid cell type and large size of tumor [63]. It is important to notice that histopathological evaluation is important for assessment; however, genetic analysis should be consulted for a more reliable information regarding the prognosis of the tumor.

Molecular risk factors include tyrosinase mRNA (the enzyme involved in the synthesis of melanin) which can be used for the indirect quantification of circulating tumor cells [69]; vascular endothelial growth factor (VEGF) which is known to be overexpressed in melanoma cases (it originates from abnormal new vessels within the tumor and hypoxia induced by the irregular blood flow) [70, 71]; the hepatocyte growth factor (which have an important role in the growth of cells in the liver) [72]; and the insulin-like growth factor-1 (which binds to IGF-1 receptor, increasing the cell proliferation, preventing apoptosis and playing an important role in integrin adhesion to the extracellular matrix and invasion of basement membranes) [73].

Gene and chromosome alterations, referred above, are a great risk factor for the development of metastases. The major chromosome alterations have been described in chromosomes 3, 6, 8 and 11 and are significantly correlated with the clinical high-risk factors for metastases, such as tumor size at diagnosis and epithelioid cell histopathology [63].

Cytogenetic alterations have enabled relevant insights regarding the pathobiology of uveal melanoma; therefore, 
several groups have studied the use of gene expression profiling (GEP) in the detection of upregulation or downregulation of select genes in a tissue sample (obtained by biopsy). The technique involves isolating RNA from a tissue sample followed by its conversion to complementary DNA, whose targets are subsequently hybridized to gene chips, and microarray analysis is performed. Taking into account gene expression profile (15-gene expression panel), uveal melanomas can be divided into two distinct prognostic classes, namely class 1 tumors (which generally have the clinical and pathological features known to be associated with decreased metastatic risk, such as the presence of spindle cells), and class 2 tumors (which generally have more aggressive clinical and pathological features, with a higher risk for metastases). This test is commercially available for routine use in clinical practice $[13,52]$.

\section{Primary treatment of uveal melanoma}

The aim of the treatment of localized uveal melanoma is to preserve the vision and avoid metastases. The therapy selected to treat uveal melanoma depends on several factors, including tumor size, lesion location, general health of the patient, and patient preference. The primary treatment of uveal melanoma includes radiotherapy (brachytherapy and proton beam radiotherapy), phototherapy (photocoagulation, transpupillary thermal therapy, and photodynamic therapy) and surgery (local resection, enucleation and exenteration) $[3,10,74-76]$.

While small- and medium-sized uveal melanomas can be successfully treated with a variety of methods, there is no consensus about the optimum management for thick $(\geq 7 \mathrm{~mm}$ ) uveal melanomas. Although enucleation has been the treatment of choice for large uveal melanomas, in certain situations, such as the presence of a tumor in only remaining eye, poor vision in the fellow eye, or whenever a patient insists on avoiding enucleation, conservative modalities can be considered to preserve the diseased eye [77].

Radiotherapy has largely replaced enucleation for tumors of suitable location and dimension (less than $10 \mathrm{~mm}$ in thickness and $18 \mathrm{~mm}$ in largest basal diameter). Regarding larger tumors, there is some risk of vision loss and radiation complications because of neovascular glaucoma. Nevertheless, radiotherapy is sometimes used in patients with large tumors and who show preference for eye-sparing treatments [78].

\section{Surgery}

Local resection of the tumor can be carried out either by a transretinal (endoresection) or transscleral (exoresection) approach $[79,80]$. Local resection is used to remove select (typically medium sized or large) uveal melanoma with retention of the eye [81]. Endoresection is more suitable for posterior uveal melanomas [82]. The complications involving these surgeries include vitreous hemorrhage and retinal detachment. Furthermore, there is some concern regarding local recurrence (risk factor for metastases) and iatrogenic tumor spread. However, these can be minimized by adjuvant radiotherapy [3]. Some centers irradiate the uveal melanoma before endoresection or place a radioactive plaque over the tumor base after transscleral resection [81].

Enucleation involves surgical removal of the eye. While it has historically been the treatment of choice, nowadays it has been shifted towards vision-sparing treatments due to recent advances in radiotherapy [3, 78]. Nevertheless, patients with lesions exceeding $10 \mathrm{~mm}$ in thickness and/ or $18 \mathrm{~mm}$ in diameter are still indicated for the treatment with enucleation because of the complications connected to delivering high doses of radiation to the eye, including vision loss and loss of the eye [78]. Furthermore, enucleation is also considered an option in patients with little chance to save vision, which is usually the case for large, advanced uveal melanoma, tumors located near the optic disc, tumors presenting with extensive bleeding or retinal detachment, or vitreous hemorrhage. In terms of survival, several studies have shown no differences in mortality rates comparing surgical treatments with conservative treatments [82].

\section{Brachytherapy}

Brachytherapy involves suturing a radioactive plaque temporarily to the episclera to deliver a fixed dose directly to the tumor [6]. Operative localization of the plaque placement is guided by translumination, ophthalmoscopic observation or ultrasonography. The surgery is performed either under local or general anesthesia. Extraocular muscles and conjunctiva are reattached not to disturb brachytherapy [3, 81]. The plaque remains in place for 2-5 days, depending on the type and activity of the radioactive source, and it is then removed under similar operative conditions. The most common radioisotopes used in the plaques are iodine-125 $\left({ }^{125} \mathrm{I}\right)$ and ruthenium-106 $\left({ }^{106} \mathrm{Ru}\right) .{ }^{106} \mathrm{Ru}$ is generally preferred in Europe, whereas ${ }^{125} \mathrm{I}$ is commonly prescribed in United States [3, 10]. Other radioisotopes include cobalt- $60\left({ }^{60} \mathrm{Co}\right)$ and palladium-103 $\left({ }^{103} \mathrm{Pd}\right)$. The choice of isotope is often based on tumor depth since they have different penetration rates [10]. ${ }^{125}$ I plaques emit gamma radiation which has deeper penetration but increased toxicity to surrounding healthy tissues. ${ }^{106} \mathrm{Ru}$ plaques emit beta radiation, having less deep penetration compared to ${ }^{125}$ I plaques, but lower toxicity to surrounding healthy tissues. Thus, due to their lower penetration, ${ }^{106} \mathrm{Ru}$ plaques are unsuitable for thick tumors, and their use is generally restricted to tumors less than $6 \mathrm{~mm}$ in apical thickness [3, 81]. According to Blum et al. [3], regular ophthalmologic examinations should be performed following brachytherapy to assess radiation-induced damage, 
including retinopathy, papillopathy, exudative retinal detachment and cataract which can develop 2-5 years following initial treatment.

Correct plaque placement is essential for good clinical outcomes. The target volume should include the tumor base and safety margin. According to Simpson et al. [81], ${ }^{106} \mathrm{Ru}$ plaques achieve larger physical safety margins than ${ }^{103} \mathrm{Pd}$ and ${ }^{125}$ I plaques. The use of eccentric plaque positioning has been shown to provide good local control for tumors within $5 \mathrm{~mm}$ of the optic disk or fovea. Slotted plaques incorporate the optic nerve into the plaque, allowing the entire tumor and a 2-mm-free margin to be encompassed by the plaque [82]. Plaque orifices should exceed the largest tumor diameter as to create a tumor-free margin of safety to prevent geographic miss [81].

There is a lack of internationally accepted dosimetry standards for each radionuclide. According to Simpson et al. [81], dose prescriptions for uveal melanoma typically range from 70 to $100 \mathrm{~Gy}$ to the tumor apex and dose rates should not be less than the COMS historical standard of $0.60 \mathrm{~Gy} / \mathrm{h}$ for ${ }^{125} \mathrm{I}$ plaques. Dose modifications may be appropriate taking into account different tumor sizes, implant durations, threshold doses to critical normal ocular structures, and the use of alternate radionuclide sources [81].

The most common radiation side effects include optic neuropathy, maculopathy, cataract, and neovascular glaucoma, numerous studies of which have shown these to be dose dependent [82].

\section{Charged-particle radiation therapy}

Charged-particle radiation therapy may be delivered using protons, carbon ions or helium ions and allows for more focused radiation treatment, collimated charged-particle beams peaking at the desired tissue depth and stopping thereafter [83]. This has dosimetric advantage since it allows for the delivery of large radiation doses for adequate tumor treatment without sparing of surrounding structures. Nevertheless, the five most commonly reported adverse effects associated with charged-particle radiation therapy were glaucoma, radiation retinopathy, cataract formation, optic neuropathy and enucleation. Furthermore, chargedparticle radiation therapy often also administers radiation to the anterior segment to reach posterior uveal melanoma tumors. Thus, a strong correlation has been shown between the percentage of lens and anterior camera involvement and the development of neovascular glaucoma [84]. However, it is possible to reduce radiation complications through certain charged-particle radiation therapy techniques, such as the utilization of notched beams, adjunctive transpupillary thermal therapy (TTT) or phototherapy, and the treatment through a closed eyelid [85]. According to uveal melanoma registries, patients with larger tumors, and tumors near the optic disk and fovea, are preferentially referred to be treated with charged-particle radiation therapy [82].

Proton beam therapy (PBT) is a type of charged particle therapy which uses proton beams. First, the patient is submitted to a surgical placement of tantalum marker rings, which are placed at the tumor border on the sclera and served as radiographic markers of the tumor edge for treatment planning and daily image guidance. This is not necessary for iris melanomas since they are visible externally. Following surgery, the position of tantalum markers is confirmed by an X-ray image [86, 87]. A 3D computer model of the eye is generated. The optimal gaze is established to minimize the dose to critical structures (optic nerve, macula, lens and cornea). The appropriate depth of beam penetration necessary to encompass the target volume is determined, dose-volume histograms are produced for each structure and dose distribution is assessed. The relationship of the rings to the beam and collimator is projected to ensure proper planned tumor coverage [86]. In choroidal melanomas, proton beam radiotherapy is administered with safety margins of 2.0-2.5 mm. Nevertheless, these can be reduced if there is risk of optic nerve and fovea damage. On the other side, as ciliary body melanomas tend to develop diffuse spread circumferentially, safety margins of up to $4 \mathrm{~mm}$ should be used in such cases. With iris melanomas, safety margins of $3 \mathrm{~mm}$ or one clock hour are advised. When iris tumor shows diffuse growth or seeding, radiotherapy should be delivered to the entire anterior segment [87]. The radiation is delivered for 4-5 days and the dose is generally 56-60 Gy in four daily fractions up to $70 \mathrm{~Gy}$ in five daily fractions [86]. After proton beam is complete, patients should be followed closely either for local recurrence as distant disease. This follow-up includes clinical examination, ocular ultrasound and liver function tests [86].

Several reports on proton beam therapy describe a 5-year local control of $95 \%$ or greater for uveal melanomas, with a 5 -year overall survival of approximately $80 \%$ (small tumors ranging 95-98\%; medium 80-86\% and large 60\%). Enucleation rates at 5 years is approximately $10 \%$ and at 15 years is approximately $15 \%$ [86].

According to Damato et al. [87], proton beam therapy has the widest inclusion criteria and can be administered as primary treatment or salvage therapy for local tumor recurrence after plaque radiotherapy, phototherapy or surgical resection.

\section{Stereotactic radiosurgery}

Stereotactic radiosurgery (SRS) uses emission of high-dose gamma radiation concentrated over a small volume [88, 89]. Radiation energy is delivered to a well-defined area with little exposure to surrounding tissue. This ability to direct radiation to a precise target is advantageous when treating tumors near the macula and optic disk [88]. SRS works by 
damaging the DNA of the target cells, which then lose the ability to reproduce, causing tumors to shrink. Furthermore, the high dose of radiation delivered causes blood vessels to close off over time following treatment, robbing the tumor of its blood supply. This technique is not a surgical procedure, requiring just local anesthesia. Thus, it is suitable for patients who are contraindicated to general anesthesia.

Sikuade et al. [88] have studied the use of SRS and PBT to treat posterior uveal melanoma over a 10 -year period. They verified that both treatments achieved excellent local control rates, concluding that these techniques are effective treatments for large choroidal melanomas or tumors unsuitable for plaque radiotherapy.

\section{Photocoagulation}

Photocoagulation uses a focused laser beam to destroy vessels that supply blood to tumor cells [90]. Nevertheless, this technique present high rates of complications and has been replaced by a more recent variation using infrared radiation called TTT $[74,82]$.

\section{Transpupillary thermal therapy}

TTT uses an infrared laser to deliver low-energy phototherapy through a dilated pupil to the tumor surface [74]. Direct cell destruction induces tumor necrosis. Since infrared radiation is only capable of penetrating the surface tumor layer, this technique is suitable for treating small tumors $(<3 \mathrm{~mm}$ in apical height and $<16 \mathrm{~mm}$ in basal largest diameter) or marginal recurrences following proton therapy $[3,78,82]$. Initially, this technique was developed as an adjunct therapy to plaque brachytherapy, but interest in TTT as a primary treatment grew since it could provide improved visual outcomes compared to plaque brachytherapy. Nevertheless, longer follow-up of initial studies using this technique as primary treatment for small posterior tumors revealed high risk of local recurrence, demonstrating its ineffectiveness in this setting. Besides that, TTT has revealed some complications, including branch retinal artery and vein occlusions, epiretinal membranes, cystoid macular edema, and optic disk swelling [82].

\section{Photodynamic therapy}

Photodynamic therapy (PTD) consists of the excitation of an intravenously administered photosensitizer by a specific wavelength applied to the target region, having non-thermal tissue effects [91]. Through cellular, vascular and immunogenic pathways, which are not completely understood, generated free radicals and highly reactive singlet oxygen species induce cell and tissue destruction. The relative contribution of each pathway is thought to be dependent upon the characteristics of the photosensitizer, the treatment tissue and treatment parameters, including time and dose. Verteporfin is a second-generation photosensitizer and its effects are thought to be attributed to a combination of vascular occlusion direct cytotoxicity and activation of the immune system. According to Pereira et al. [82] there is some evidence that PDT is more effective in lightly pigmented melanomas, than more densely pigmented tumors. Despite the limited clinical experience with PDT, small series using PDT with verteporfin as primary therapy have shown to be effective in achieving complete regression [92]. Moreover, its use as second-line therapy evidenced partial effect in one study. Nevertheless, histopathologic studies of three cases of uveal melanoma 1 week after treatment with PDT (with verteporfin) and bevacizumab showed viable melanoma cell with no necrosis. Thus, the authors concluded that PDT is not effective in the treatment of these uveal melanomas. Further studies are needed to determine optimal case-selection criteria, treatment parameters, and the efficacy of PDT with verteporfin as a primary or adjuvant treatment for uveal melanoma [82]. Table 1 summarizes the available treatment options of uveal melanoma.

\section{Adjuvant therapy}

Adjuvant therapy consists of radiotherapy or systemic therapy, such as immunotherapy, chemotherapy and targeted therapy. Nevertheless, there are few studies related to adjuvant therapy in uveal melanoma and according to Pereira et al. [82] more studies with promising systemic therapies and combination treatments are still needed.

\section{Treatment of metastatic uveal melanoma}

Approximately half of patients with primary uveal melanoma will develop metastases. Although there are effective therapies to eradicate and prevent local recurrence of primary uveal melanomas, there is no current effective treatment for metastatic uveal melanoma. Thus, the long-term prognosis of metastatic disease is very poor. The median survival time from the development of distant metastases is between 4 and 15 months, and the 1-year survival rate is $10-15 \%$. Nevertheless, several treatments have been studied, including chemotherapy, immunotherapy and molecular targeted therapy $[3,93]$.

\section{Systemic chemotherapy}

Response rates of metastatic uveal melanoma to systemic chemotherapy are poor and survival rates of metastatic uveal melanoma have remained almost unchanged in the past 40 years. When metastatic uveal melanoma is restricted to a limited anatomic region, locoregional treatment modalities, 
Table 1 Summary of available treatment options for uveal melanoma

\begin{tabular}{|c|c|c|}
\hline Treatment & Used for & Comments \\
\hline \multicolumn{3}{|l|}{ Radiotherapy } \\
\hline Brachytherapy ${ }^{106} \mathrm{Ru}$ & Small/medium/large uveal melanoma & - \\
\hline Brachytherapy ${ }^{125} \mathrm{I}$ & $<20 \mathrm{~mm}$ in basal diameter & - \\
\hline Proton beam therapy & $\begin{array}{l}\text { Medium-to-large uveal melanoma, which cannot be } \\
\text { treated with brachytherapy or resection }\end{array}$ & - \\
\hline Stereotactic radiosurgery & $\begin{array}{l}\text { Juxtapapillary uveal melanoma; patients unsuitable for } \\
\text { brachytherapy or surgery }\end{array}$ & Lower availability \\
\hline \multicolumn{3}{|l|}{ Phototherapy } \\
\hline Transpupillary thermal therapy & $\begin{array}{l}\text { Local recurrence and of adjuvant therapy of uveal } \\
\text { melanoma }\end{array}$ & $\begin{array}{l}\text { Very occasionally used; when considering pres- } \\
\text { ervation of vision since it avoids radiotherapy } \\
\text { complications, it is not recommended routinely } \\
\text { as a sole primary treatment }\end{array}$ \\
\hline Photodynamic therapy & Small melanomas & Avoids radiotherapy complications \\
\hline \multicolumn{3}{|l|}{ Surgery } \\
\hline Exoresection \pm plaque & $\begin{array}{l}\text { Medium-to-large melanoma with a narrow basal } \\
\text { diameter }\end{array}$ & $\begin{array}{l}\text { Rarely performed; always performed with brachy- } \\
\text { therapy to reduce the risk of recurrence }\end{array}$ \\
\hline Endoresection \pm radiotherapy & Medium-sized uveal melanoma & - \\
\hline Enucleation & Large uveal melanoma & - \\
\hline
\end{tabular}

such as surgical resection, intraarterial chemotherapy, transarterial percutaneous chemoembolization, selective internal radiation therapy, and radiofrequency ablation can be used to control the disease [7]. A variety of cytotoxic agents have been investigated, including dacarbazine, treosulfan, temozolomide, fotemustine, cisplatin, and combination therapies such as bleomycin, vincristine, lomustine, and dacarbazine, gemcitabine/treosulfan and dacarbazine/treosulfan. Nevertheless, in clinical practice responses are rarely seen and overall survival is questionable [94]. The survival remains between 2 and 7 months, with only $15 \%$ of patients resist about 1 year. Higher response rates and median survival have been observed with chemotherapy administration directly to the hepatic artery [82]. A better understanding of melanoma molecular biology has been critical in developing new treatments. New chemotherapeutic agents tested in uveal melanoma include docosahexaenoic acid-paclitaxel (a covalent conjugate of paclitaxel and docosahexaenoic acid) and vincristine sulfate liposome infusion (sphingomyelin/ cholesterol liposome-encapsulated formulation of vincristine that results in extended drug circulation time and anticancer activity). Both treatments have shown limited responses in patients with uveal melanoma [82].

There are several clinical trials studying chemotherapy for the treatment of metastatic uveal melanoma or as adjuvant therapy of primary uveal melanoma.

\section{Systemic immunotherapy}

The eye is considered an immune-privileged organ which influences the immune response against uveal melanoma cells and provides escape mechanisms for uveal melanoma [95]. The following factors play an important role in the immune privilege of the eye: aqueous humor is rich in immunosuppressive proteins, such as transforming growth factor $\beta$ (TGF- $\beta$ ), vasoactive intestinal peptide (VIP), $\alpha$-melanocyte-stimulating hormone ( $\alpha$-MSH), and complement regulatory proteins (CRPs); the blood-eye barrier restricts inflammatory cell access to the eye; eye cells reduce major histocompatibility complex (MHC) class Ia expression to escape cytotoxic-mediated lyses; and ocular cells express programmed death ligand-1(PD-L1) which inhibits $\mathrm{T}$-cell response. Thus, a deeper understanding of the interaction between immune and cancer cells is crucial to take the maxim benefit of immunotherapy [16].

Uveal melanoma cells impair the innate immunity through inhibition of the action of natural killer (NK) cells by the production of macrophage inhibiting factor (MIF) and TGF- $\beta$ and MHC class I upregulation. Furthermore, uveal melanoma cells produce cytokines that lead to macrophage differentiation to M2 subtype, which promotes tumor growth instead of an effective immune response. To date, there are no treatments that target NK cells or macrophages. Regarding adaptive immune response, the mechanisms that interfere with immunity are the production of indoleamine 2,3-dioxygenase (IDO), overexpression of PD-L1, alteration of FasL expression, and resistance to perforin [16, 95].

Uveal melanoma cells overexpress the PD-L1 receptor when exposed to interferon- $\gamma$ (INF- $\gamma$ ), an immunostimulatory cytokine, with consequent suppression of $\mathrm{T}$ cells by decreasing IL-2 production. Uveal melanoma cells come in contact with IFN- $\gamma$ produced in the new organ when 
they metastasize, thus uveal melanoma cells do not express PD-L1 constitutively when they are in the immune-privileged microenvironment of the eye [16]. Although antiPD1 antibodies nivolumab and pembrolizumab have been approved by the FDA for the treatment metastatic cutaneous melanoma, there are no available results with anti-PD1 or anti-PD-L1 in metastatic uveal melanoma $[3,16]$. There are only a limited number of clinical trials exploring this strategy, namely a phase II trial studying pembrolizumab in monotherapy, and two phase II trials studying the combinations of nivolumab and ipilimumab [96].

An antibody against cytotoxic T-lymphocyte-associated protein-4 (CTLA-4), ipilimumab, has been approved to treat patients with metastatic uveal melanoma in the setting of immunotherapy. CTLA-4 is expressed by activated T cells and transmits an inhibitory signal to $\mathrm{T}$ cells, downregulating immune responses. Although experience with ipilimumab in metastatic uveal melanoma is limited [97], it has demonstrated good overall survival and long-term survival in a proportion of patients [16]. More recently, a combination of nivolumab and ipilimumab exhibited efficacy against metastatic skin melanoma with limited toxicity; however, no evidence on its successful use for the treatment of metastatic uveal melanoma has been reported yet [98]. In a phase $1 \mathrm{~b} / 2$ study of PV-10 (a small oncolytic immunotherapy molecule under development for solid tumors) in combination with pembrolizumab has been run in patients with advanced melanoma (stage IIIC-IV M1c) [99]. In the first 10 patients, the preliminary data of this study showed about $50 \%$ of response rate.

\section{Molecular targeted therapy}

As a result of increased understanding of the oncogenic drivers in uveal melanoma several promising therapeutic targets have been identified. Targeted therapy is currently one of the most studied strategies for the treatment of cancer aiming at reducing the risk of systemic toxicity. It applies drugs that interfere with specific molecules involved in cell tumor progression and proliferation and, thus, blocks specific pathways to the growth and evolution of cancer cells [82].

Since MAPK pathway is activated in the majority of uveal melanomas, due to GNAQ/GNA11 mutations, inhibitors of downstream effectors, such as MEK and protein kinase $\mathrm{C}$ (PKC), are currently under investigation. MEK inhibitors include trametinib and selumetinib. Both have shown clinical activity in clinical trials. A randomized phase II clinical trial showed that selumetinib-treated patients had better responses rates (14\%) and improved progression-free survival (PFS) compared to those who received temozolomide or dacarbazine chemotherapy. Nevertheless, other study of selumetinib plus dacarbazine versus dacarbazine alone did not show a statistically significant improvement in PFS. A study of the combination of a MEK inhibitor with an Akt inhibitor demonstrated that MEK inhibition is sensitized by Akt inhibition [3, 82].

C-kit is a transmembrane receptor with tyrosine kinase activity that acts in differentiation, proliferation and programmed cell death and has been shown to be overexpressed in uveal melanoma, being a potential oncogenic driver in this type of tumor. Imatinib is a c-kit inhibitor which demonstrated, in vitro, to decrease the invasion capability of uveal melanoma cells [3, 82]. Nevertheless, according to Pereira et al. [82], further studies are needed to address its effect in the treatment of primary uveal melanoma, especially in high-risk patients. Sunitinib is a non-selective c-kit inhibitor that did not show improvement in PFS or overall survival in the SUAVE trial, a phase II clinical trial [100].

C-met inhibitors have also been studied as a therapy to treat uveal melanoma. Inhibition of c-met was shown to prevent tumor growth in preclinical models of uveal melanoma. Cabozantinib is an example of a c-met inhibitor.

Loss of $B A P 1$ seems to be a difficult therapeutic challenge since it appears to represent a loss of a tumor suppressor, and direct therapies will require the re-initiation of function. Nevertheless, some treatment options, which have this mutation as target, have been studied. A study showed that $B A P 1$ loss results in an accumulation of mono-ubiquitin on histone $\mathrm{H} 2 \mathrm{~A}$, altering the transcriptional profile within these cells. The use of histone deacetylase inhibitors (HDACis), such as valproic acid, can reverse the accumulation of monoubiquitin [45].

Tumour angiogenesis is essential for tumor growth, progression and metastasis. VEGF is one of the major cytokines that influence tumor angiogenesis and can serve as a biomarker for metastatic UM since it appears to be significantly increased after metastatic development in uveal melanoma patients. Bevacizumab is a monoclonal anti-VEGF antibody that was shown to suppress in vivo hepatic micrometastasis [82].

\section{Liver-directed therapies}

Liver is the most common place of metastases resulting from uveal melanoma, while the clinical course of patients with liver metastases is dependent on the disease progression in the liver. Whole-body PET/CT was shown to be sensitive enough for the detection of liver and extra-hepatic metastases. Several approaches have been used to treat metastatic liver disease, including resection, immune embolization, chemoembolization, radioembolization, isolated hepatic perfusion and percutaneous hepatic perfusion. However, there is no standard treatment for liver metastases [82].

Resection consists of the surgical removal of metastatic nodules and has been shown to improve the survival of patients with liver metastases of uveal melanoma, either by 
single or multiple resections. Nevertheless, the presence of multiple liver metastases is a contraindication for major liver resection and, thus, only a limited number of patients are eligible for surgical treatment [82].

Chemoembolization combines artery embolization with the infusion of chemotherapeutic agents [101]. This treatment has shown to improve the overall survival of patients with liver metastatic disease. Although chemoembolization has been used for the treatment of liver metastases from uveal melanoma, there are no standard protocols and comparative trials demonstrating superior results of one particular chemotherapeutic agent over another. Several chemotherapeutic agents have been used for chemoembolization, including cisplatin alone and in combination with carboplatin, carboplatin in monotherapy, 1,3-bis(2-chloroethyl)1-nitrosourea (BCUN) and mitomycin $\mathrm{C}$ alone and in combination with cisplatin and doxorubicin [102].

Immunoembolization consists of infusion of an immunestimulating agent into the hepatic artery followed by embolization [103]. Despite the abundance of immune cells, the liver tends to induce tolerance rather than immunity. Thus, the objective of immunoembolization is to destroy the tumor by embolization and, thus to control the tumor progression locally and to provide tumor antigens to the local immune system. It acts as local stimulation of the immune system which results in the development of a systemic immune response against tumor cells that may suppress the tumor growth [102]. Granulocyte-macrophage colony-stimulating factor (GM-CSF) is a glycoprotein secreted by the T cells that stimulates immune cells, such as macrophages and dendritic cells, and it has been used for immunoembolization of metastatic uveal melanoma, demonstrating to be well tolerated and with acceptable toxicity profiles $[82,104]$.

Radioembolization using yttrium-90 $\left({ }^{90} \mathrm{Y}\right)$ has been applied to treat patients with liver metastases from uveal melanoma. ${ }^{90} \mathrm{Y}$ is delivered to the liver through two types of microspheres, namely TheraSpheres (nonbiodegradable glass microspheres with a diameter of 20-30 $\mu \mathrm{m}$ ) and SIRSpheres (nonbiodegradable resin ${ }^{90} \mathrm{Y}$ microspheres with a diameter of 20-40 $\mu \mathrm{m})$ [105]. Since SIR-Spheres exhibit lower activity (40-70 Bq per microsphere) compared to TheraSpheres (maximum $2500 \mathrm{~Bq}$ ), more SIR-Spheres are necessary to deliver a similar dose. Nevertheless, the higher number of SIR-Spheres allows providing an embolic effect in addition to delivering radiation directly to the tumors. This is advantageous when tumors are hypervascular, numerous and dispersed throughout both lobes of liver [102].

Isolated hepatic perfusion (IHP) is a procedure where the liver is surgically isolated and perfused with a high concentration of the chemotherapeutic agent [106]. This technique allows local perfusion of the liver with a high dose of a chemotherapeutic agent, without the leakage of systemic circulation, thus, avoiding undesirable systemic effects. The isolated hepatic perfusion of melphalan has been studied. Nevertheless, IHP requires a complex surgical procedure with considerable morbidity and mortality, which is largely related to veno-occlusive disease and hepatotoxicity $[82,106]$.

Percutaneous hepatic perfusion (PHP) with simultaneous chemofiltration has been developed as an alternative to IHP since it decreases morbidity and mortality and can be repeated leading to a higher response rate and improved survival (by local control of the disease). PHP involves the placement of two catheters, one in the proper hepatic artery, to infuse the chemotherapeutic agent and the other in the inferior caval vein, to aspirate the chemosaturated blood returning through the hepatic veins and to avoid the leakage into the systemic circulation. Simultaneously, the blood returning from the hepatic veins is perfused through an extra-corporeal filtration system. After filtration, the blood is returned to the patient by a third catheter in the right internal jugular vein. Hemodynamic monitoring and hemodynamic support are advised because of the hemodynamic instability resulting from this complex procedure [107]. Current clinical trials on uveal melanoma management are summarized in Table 2.

Recognising that adoptive T-cell therapy has shown positive responses in multiple refractory solid tumors; in a study conducted by Chandran et al., adoptive transfer of autologous tumor-infiltrating lymphocytes (TIL) was evaluated as a mean to mediate regression of metastatic uveal melanoma [108]. Patients with histologically confirmed metastatic ocular melanoma were enrolled in the study. Metastasectomy was carried out to collect tumor tissue for autologous TIL culturing, for further ex vivo expansion. Patients were then treated with lymphodepleting chemotherapy followed by intravenous infusion of autologous TIL and interleukin-2. Seven out of 20 patients exhibited objective tumor regression. Among the responders, six achieved partial response, whereas one achieved complete response of numerous hepatic metastases. The obtained results from this clinical study raise the question if indeed metastatic uveal melanoma is immunotherapy resistant, thereby supporting the need for research on immune-based therapies for uveal melanoma. An alternative approach to immunotherapy has been proposed by the use of a novel immune-based treatment, IMCgp100. This treatment has shown 1-year survival rates of $73 \%$ for patients with advanced uveal melanoma [109]. IMCgp100 exhibits one end with a soluble affinity-enhanced T-cell receptor targeting the melanocyte lineage protein gp100 bound to HLA A201, and an anti-CD3 scFv as the other end. This configuration allows the molecule to redirect $\mathrm{T}$ cells into uveal melanoma, ultimately leading to T-cell activation and tumor cell killing. 
Table 2 Current status of on-going and planned clinical trials on uveal melanoma (source: http://inclinicaltrials.com)

\begin{tabular}{|c|c|c|c|c|}
\hline Identification number & Clinical trial & Status & Starting date & Phase \\
\hline NCT03712904 & $\begin{array}{l}\text { Stereotactic body radiation therapy and aflibercept in treating } \\
\text { patients with uveal melanoma }\end{array}$ & Not yet recruiting & December 25, 2019 & Phase 2 \\
\hline NCT03022565 & Vorinostat in patients with class 2 high-risk uveal melanoma & Recruiting & July 2019 & Early phase 1 \\
\hline NCT03417739 & A phase II study of BVD-523 in metastatic uveal melanoma & Recruiting & March 26, 2018 & Phase 2 \\
\hline NCT03070392 & $\begin{array}{l}\text { Safety and efficacy of IMCgp100 versus investigator choice in } \\
\text { advanced uveal melanoma }\end{array}$ & Recruiting & October 16, 2017 & Phase 2 \\
\hline NCT03052127 & Study in subjects with small primary choroidal melanoma & Recruiting & February 27, 2017 & $\begin{array}{l}\text { Phase } 1 \\
\text { Phase } 2\end{array}$ \\
\hline NCT02936388 & $\begin{array}{l}\text { Transarterial radioembolization in comparison to transarterial } \\
\text { chemoembolization in uveal melanoma liver metastasis }\end{array}$ & Recruiting & January 2016 & Phase 2 \\
\hline NCT02913417 & $\begin{array}{l}\text { Yttrium-90, ipilimumab, and nivolumab for uveal melanoma } \\
\text { with liver metastases }\end{array}$ & Recruiting & October 2016 & $\begin{array}{l}\text { Phase } 1 \\
\text { Phase } 2\end{array}$ \\
\hline NCT02874040 & $\begin{array}{l}\text { Endoresection of the tumor scar or transpupillary thermotherapy } \\
\text { for the treatment of large uveal melanomas (endoresection- } \\
\text { laser) }\end{array}$ & Recruiting & April 19, 2013 & N/A \\
\hline NCT01983748 & Dendritic cells plus autologous tumor RNA in uveal melanoma & Recruiting & June 2014 & Phase 3 \\
\hline NCT01438658 & $\begin{array}{l}\text { Assessing the clinical effectiveness of serum biomarkers in the } \\
\text { diagnosis of metastatic uveal melanoma }\end{array}$ & Recruiting & September 2011 & N/A \\
\hline NCT00872391 & $\begin{array}{l}\text { Hypofractionated stereotactic linear accelerator radiotherapy of } \\
\text { uveal melanoma }\end{array}$ & Recruiting & March 2009 & N/A \\
\hline
\end{tabular}

\section{Conclusions}

Uveal melanoma is a rare disease which can be developed from the anterior (iris) or posterior uveal tract (ciliary body and choroid). A variety of therapeutic options are available to treat primary uveal melanoma, such as surgery and radiotherapy. Several studies have shown that either conservative or radical (enucleation) treatments are not associated with a definitive survival benefit. This is one of the reasons that enucleation has been largely replaced by conservative modalities such as brachytherapy, proton beam radiation, stereotactic radiotherapy and tumor resection in recent years. These conservative treatments, contrary to enucleation, allow for eye preservation. Among them, brachytherapy is the technique of choice. Enucleation is preferred for larger tumors and when there is a little chance to save vision. Nonetheless, approximately half of patients with primary uveal melanoma will develop metastases, especially to the liver. Metastases are the main cause of mortality among patients with uveal melanoma and are a poor prognostic factor. More specific therapies have been used for the treatment of metastatic uveal melanoma, including systemic chemotherapy, immunotherapy, molecular targeted therapy and liver-directed therapies. Nevertheless, systemic chemotherapy has not improved the overall survival time in patients with uveal melanoma. Regarding molecular target therapy, the results are not constant, with different clinical trials with the same drugs showing different conclusions. The diversity of pathways involved in the metastatic uveal melanoma makes it difficult to find a specific effective drug for this highly lethal tumor. The main challenge of uveal melanoma management is to find an effective therapy for the high percentage of metastases observed in this pathology. Several clinical trials have been run worldwide to solve this problem. The better understanding of molecular biology of uveal melanoma has allowed developing new promising systemic therapies. However, further studies are needed to find an effective strategy to treat metastatic uveal melanoma. The combination of different therapies, which have different targets involved in uveal melanoma, may be a good alternative for this lethal tumor.

Acknowledgements The authors wish to acknowledge the financial support received from Portuguese Science and Technology Foundation (FCT/MCT) and from European Funds (PRODER/COMPETE) under the projects M-ERA-NET-0004/2015-PAIRED and UID/ AGR/04033/2019 (CITAB), co-financed by FEDER, under the Partnership Agreement PT2020. The authors wish to acknowledge the contribution of the Master Student Ms. Irina Pereira in the reading of the manuscript.

\section{Compliance with ethical standards}

Conflict of interest The authors confirm that there is no conflict of interest with respect to the publication of this review.

Ethical approval This article does not contain any studies with human participants or animals performed by any of the authors. We also confirm that no ethical issues are raised in this work. The research does not involve experiments with humans or with animals.

Informed consent No inform consent for human participation is needed. 


\section{References}

1. Singh AD, Bergman L, Seregard S (2005) Uveal melanoma: epidemiologic aspects. Ophthalmol Clin N Am 18(1):75-84. https ://doi.org/10.1016/j.ohc.2004.07.002

2. Stei MM, Loeffler KU, Holz FG, Herwig MC (2016) Animal models of uveal melanoma: methods, applicability, and limitations. Biomed Res Int. https://doi.org/10.1155/2016/4521807

3. Blum ES, Yang J, Komatsubara KM, Carvajal RD (2016) Clinical management of uveal and conjunctival melanoma. Oncology (Williston Park) 30(1):29-32 (34-43, 48)

4. Krantz BA, Dave N, Komatsubara KM, Marr BP, Carvajal RD (2017) Uveal melanoma: epidemiology, etiology, and treatment of primary disease. Clin Ophthalmol 11:279-289. https://doi. org/10.2147/OPTH.S89591

5. Dogrusoz M, Jager MJ, Damato B (2017) Uveal melanoma treatment and prognostication. Asia Pac J Ophthalmol (Phila) 6(2):186-196. https://doi.org/10.22608/apo.201734

6. Kaliki S, Shields CL (2017) Uveal melanoma: relatively rare but deadly cancer. Eye (Lond) 31(2):241-257. https://doi. org/10.1038/eye.2016.275

7. Buder K, Gesierich A, Gelbrich G, Goebeler M (2013) Systemic treatment of metastatic uveal melanoma: review of literature and future perspectives. Cancer Med 2(5):674-686. https://doi. org/10.1002/cam4.133

8. Ross MH, Pawlina W (2011) Eye. In: Histology: a text and atlas: with correlated cell and molecular biology, 6th edn. Wolters Kluwer Health/Lippincott Williams \& Wilkins, Philadelphia, pp 896-919

9. PDQ Adult Treatment Editorial Board (2018) Intraocular (uveal) melanoma treatment, PDQ Cancer Information Summaries [Internet]. National Cancer Institute (US), Bethesda (MD)

10. Kapoor A, Beniwal V, Beniwal S, Mathur H, Kumar HS (2016) Management of uveal tract melanoma: a comprehensive review. J Egypt Natl Cancer Inst 28(2):65-72

11. Collaborative Ocular Melanoma Study G (2003) Comparison of clinical, echographic, and histopathological measurements from eyes with medium-sized choroidal melanoma in the collaborative ocular melanoma study: COMS report no 21. Arch Ophthalmol 121(8):1163-1171. https://doi.org/10.1001/archopht.121.8.1163

12. Onken MD, Li J, Cooper JA (2014) Uveal melanoma cells utilize a novel route for transendothelial migration. PLoS One 9(12):115472-115488

13. Harbour JW (2012) The genetics of uveal melanoma: an emerging framework for targeted therapy. Pigment Cell Melanoma Res 25(2):171-181

14. Diener-West M, Reynolds SM, Agugliaro DJ, Caldwell R, Cumming K, Earle JD, Hawkins BS, Hayman JA, Jaiyesimi I, Jampol LM, Kirkwood JM, Koh WJ, Robertson DM, Shaw JM, Straatsma BR, Thoma J, Collaborative Ocular Melanoma Study G (2005) Development of metastatic disease after enrollment in the COMS trials for treatment of choroidal melanoma: Collaborative Ocular Melanoma Study Group Report No. 26. Arch Ophthalmol 123(12):1639-1643. https://doi.org/10.1001/archo pht.123.12.1639

15. Mahendraraj K, Lau CS, Lee I, Chamberlain RS (2016) Trends in incidence, survival, and management of uveal melanoma: a population-based study of 7,516 patients from the Surveillance, Epidemiology, and End Results database (1973-2012). Clin Ophthalmol 10:2113-2119. https://doi.org/10.2147/OPTH.S113623

16. Oliva M, Rullan AJ, Piulats JM (2016) Uveal melanoma as a target for immune-therapy. Ann Transl Med 4(9):172-182

17. Jovanovic P, Mihajlovic M, Djordjevic-Jocic J, Vlajkovic S, Cekic S, Stefanovic V (2013) Ocular melanoma: an overview of the current status. Int J Clin Exp Pathol 6(7):1230-1244
18. McLaughlin CC, Wu XC, Jemal A, Martin HJ, Roche LM, Chen VW (2005) Incidence of noncutaneous melanomas in the U.S. Cancer 103(5):1000-1007. https://doi.org/10.1002/ cncr.20866

19. Shields CL, Furuta M, Thangappan A, Nagori S, Mashayekhi A, Lally DR, Kelly CC, Rudich DS, Nagori AV, Wakade OA, Mehta S, Forte L, Long A, Dellacava EF, Kaplan B, Shields JA (2009) Metastasis of uveal melanoma millimeter-by-millimeter in 8033 consecutive eyes. Arch Ophthalmol 127(8):989-998. https://doi. org/10.1001/archophthalmol.2009.208

20. Nabil A-A, Marie S, Marc-Henri S, Nathalie C, Laurence D, Sophie P-N, Olivier L, Sergio R-R (2015) Upcoming translational challenges for uveal melanoma. Br J Cancer 113(9):1249-1253

21. Amaro A, Gangemi R, Piaggio F, Angelini G, Barisione G, Ferrini S, Pfeffer U (2017) The biology of uveal melanoma. Cancer Metastasis Rev 36(1):109-140. https://doi.org/10.1007/s1055 5-017-9663-3

22. Reichstein D (2017) New concepts in the molecular understanding of uveal melanoma. Curr Opin Ophthalmol 28(3):219-227. https://doi.org/10.1097/icu.0000000000000366

23. Patel KA, Edmondson ND, Talbot F, Parsons MA, Rennie IG, Sisley K (2001) Prediction of prognosis in patients with uveal melanoma using fluorescence in situ hybridisation. Br J Ophthalmol 85(12):1440-1444

24. Ehlers JP, Worley L, Onken MD, Harbour JW (2008) Integrative genomic analysis of aneuploidy in uveal melanoma. Clin Cancer Res 14(1):115-122. https://doi.org/10.1158/1078-0432. CCR-07-1825

25. Scholes AG, Damato BE, Nunn J, Hiscott P, Grierson I, Field JK (2003) Monosomy 3 in uveal melanoma: correlation with clinical and histologic predictors of survival. Invest Ophthalmol Vis Sci 44(3):1008-1011

26. Damato B, Dopierala JA, Coupland SE (2010) Genotypic profiling of 452 choroidal melanomas with multiplex ligation-dependent probe amplification. Clin Cancer Res 16(24):6083-6092. https://doi.org/10.1158/1078-0432.CCR-10-2076

27. Onken MD, Worley LA, Person E, Char DH, Bowcock AM, Harbour JW (2007) Loss of heterozygosity of chromosome 3 detected with single nucleotide polymorphisms is superior to monosomy 3 for predicting metastasis in uveal melanoma. Clin Cancer Res 13(10):2923-2927. https://doi.org/10.1158/10780432.CCR-06-2383

28. Damato B, Duke C, Coupland SE, Hiscott P, Smith PA, Campbell I, Douglas A, Howard P (2007) Cytogenetics of uveal melanoma: a 7-year clinical experience. Ophthalmology 114(10):19251931. https://doi.org/10.1016/j.ophtha.2007.06.012

29. Damato B, Dopierala J, Klaasen A, van Dijk M, Sibbring J, Coupland SE (2009) Multiplex ligation-dependent probe amplification of uveal melanoma: correlation with metastatic death. Invest Ophthalmol Vis Sci 50(7):3048-3055. https://doi.org/10.1167/ iovs.08-3165

30. Shields CL, Ganguly A, Bianciotto CG, Turaka K, Tavallali A, Shields JA (2011) Prognosis of uveal melanoma in 500 cases using genetic testing of fine-needle aspiration biopsy specimens. Ophthalmology 118(2):396-401. https://doi.org/10.1016/j.ophth a.2010.05.023

31. Kaliki S, Shields CL, Shields JA (2015) Uveal melanoma: estimating prognosis. Indian J Ophthalmol 63(2):93-102. https://doi. org/10.4103/0301-4738.154367

32. Harbour JW, Onken MD, Roberson EDO, Duan S, Cao L, Worley LA, Council ML, Matatall KA, Helms C, Bowcock AM (2010) Frequent mutation of BAP1 in metastasizing uveal melanomas. Science 330(6009):1410-1413

33. Van Raamsdonk CD, Bezrookove V, Green G, Bauer J, Gaugler L, O’Brien JM, Simpson EM, Barsh GS, Bastian BC (2009) Frequent somatic mutations of GNAQ in uveal melanoma and blue 
naevi. Nature 457(7229):599-602. https://doi.org/10.1038/natur $\mathrm{e} 07586$

34. Van Raamsdonk CD, Griewank KG, Crosby MB, Garrido MC, Vemula S, Wiesner T, Obenauf AC, Wackernagel W, Green G, Bouvier N, Sozen MM, Baimukanova G, Roy R, Heguy A, Dolgalev I, Khanin R, Busam K, Speicher MR, O’Brien J, Bastian BC (2010) Mutations in GNA11 in uveal melanoma. N Engl J Med 363(23):2191-2199. https://doi.org/10.1056/NEJMoa1000 584

35. Patel SP, Kim DW, Lacey CL, Hwu P (2016) GNA11 mutation in a patient with cutaneous origin melanoma: a case report. Medicine (Baltimore) 95(4):2336-2340

36. Yu F-X, Luo J, Mo J-S, Liu G, Kim YC, Meng Z, Zhao L, Peyman G, Ouyang H, Jiang W (2014) Mutant Gq/11 promote uveal melanoma tumorigenesis by activating YAP. Cancer Cell 25(6):822-830

37. Luke JJ, Triozzi PL, McKenna KC, Van Meir EG, Gershenwald JE, Bastian BC, Gutkind JS, Bowcock AM, Streicher HZ, Patel PM (2015) Biology of advanced uveal melanoma and next steps for clinical therapeutics. Pigment Cell Melanoma Res 28(2):135-147

38. Feng X, Degese MS, Iglesias-Bartolome R, Vaque JP, Molinolo AA, Rodrigues M, Zaidi MR, Ksander BR, Merlino G, Sodhi A, Chen Q, Gutkind JS (2014) Hippo-independent activation of YAP by the GNAQ uveal melanoma oncogene through a trioregulated rho GTPase signaling circuitry. Cancer Cell 25(6):831845. https://doi.org/10.1016/j.ccr.2014.04.016

39. Xu X, Wei WB, Li B, Gao F, Zhang Z, Jonas JB (2014) Oncogenic GNAQ and GNA11 mutations in uveal melanoma in Chinese. PLoS One 9(10):109699-109705

40. Field MG, Harbour JW (2014) Recent developments in prognostic and predictive testing in uveal melanoma. Curr Opin Ophthalmol 25(3):234-239

41. Landreville S, Agapova OA, Matatall KA, Kneass ZT, Onken MD, Lee RS, Bowcock AM, Harbour JW (2012) Histone deacetylase inhibitors induce growth arrest and differentiation in uveal melanoma. Clin Cancer Res 18(2):408-416. https://doi. org/10.1158/1078-0432.CCR-11-0946

42. Abdel-Rahman MH, Pilarski R, Cebulla CM, Massengill JB, Christopher BN, Boru G, Hovland P, Davidorf FH (2011) Germline BAP1 mutation predisposes to uveal melanoma, lung adenocarcinoma, meningioma, and other cancers. J Med Genet 48(12):856-859. https://doi.org/10.1136/jmedgenet-2011-10015 6

43. Testa JR, Cheung M, Pei J, Below JE, Tan Y, Sementino E, Cox NJ, Dogan AU, Pass HI, Trusa S, Hesdorffer M, Nasu M, Powers A, Rivera Z, Comertpay S, Tanji M, Gaudino G, Yang H, Carbone M (2011) Germline BAP1 mutations predispose to malignant mesothelioma. Nat Genet 43(10):1022-1025. https:// doi.org/10.1038/ng.912

44. Wiesner T, Obenauf AC, Murali R, Fried I, Griewank KG, Ulz $\mathrm{P}$, Windpassinger C, Wackernagel W, Loy S, Wolf I, Viale A, Lash AE, Pirun M, Socci ND, Rutten A, Palmedo G, Abramson D, Offit K, Ott A, Becker JC, Cerroni L, Kutzner H, Bastian BC, Speicher MR (2011) Germline mutations in BAP1 predispose to melanocytic tumors. Nat Genet 43(10):1018-1021. https://doi. org/10.1038/ng.910

45. Woodman SE (2012) Metastatic uveal melanoma: biology and emerging treatments. Cancer J 18(2):148-152

46. Abdel-Rahman MH, Boru G, Massengill J, Salem MM, Davidorf FH (2010) MET oncogene inhibition as a potential target of therapy for uveal melanomas. Invest Ophthalmol Vis Sci 51(7):3333-3339. https://doi.org/10.1167/iovs.09-4801

47. Topcu-Yilmaz P, Kiratli H, Saglam A, Soylemezoglu F, Hascelik G (2010) Correlation of clinicopathological parameters with HGF, c-Met, EGFR, and IGF-1R expression in uveal melanoma. Melanoma Res 20(2):126-132. https://doi. org/10.1097/CMR.0b013e328335a916

48. Economou MA, Andersson S, Vasilcanu D, All-Ericsson C, Menu E, Girnita A, Girnita L, Axelson M, Seregard S, Larsson O (2008) Oral picropodophyllin (PPP) is well tolerated in vivo and inhibits IGF-1R expression and growth of uveal melanoma. Invest Ophthalmol Vis Sci 49(6):2337-2342. https ://doi.org/10.1167/iovs.07-0819

49. Hausler T, Stang A, Anastassiou G, Jockel KH, Mrzyk S, Horsthemke B, Lohmann DR, Zeschnigk M (2005) Loss of heterozygosity of $1 \mathrm{p}$ in uveal melanomas with monosomy 3 . Int $\mathrm{J}$ Cancer 116(6):909-913. https://doi.org/10.1002/ijc.21086

50. Kilic E, Naus NC, van Gils W, Klaver CC, van Til ME, Verbiest MM, Stijnen T, Mooy CM, Paridaens D, Beverloo HB, Luyten GP, de Klein A (2005) Concurrent loss of chromosome arm $1 \mathrm{p}$ and chromosome 3 predicts a decreased disease-free survival in uveal melanoma patients. Invest Ophthalmol Vis Sci 46(7):2253-2257. https://doi.org/10.1167/iovs.04-1460

51. Onken MD, Worley LA, Harbour JW (2008) A metastasis modifier locus on human chromosome $8 p$ in uveal melanoma identified by integrative genomic analysis. Clin Cancer Res 14(12):3737-3745. https://doi.org/10.1158/1078-0432. CCR-07-5144

52. Correa ZM (2016) Assessing prognosis in uveal melanoma. Cancer Control 23(2):93-98

53. van den Bosch T, van Beek JG, Vaarwater J, Verdijk RM, Naus NC, Paridaens D, de Klein A, Kilic E (2012) Higher percentage of FISH-determined monosomy 3 and $8 \mathrm{q}$ amplification in uveal melanoma cells relate to poor patient prognosis. Invest Ophthalmol Vis Sci 53(6):2668-2674. https://doi.org/10.1167/ iovs.11-8697

54. Martin M, Masshofer L, Temming P, Rahmann S, Metz C, Bornfeld N, van de Nes J, Klein-Hitpass L, Hinnebusch AG, Horsthemke B, Lohmann DR, Zeschnigk M (2013) Exome sequencing identifies recurrent somatic mutations in EIF1AX and SF3B 1 in uveal melanoma with disomy 3. Nat Genet 45(8):933-936. https://doi.org/10.1038/ng.2674

55. Ewens KG, Kanetsky PA, Richards-Yutz J, Purrazzella J, Shields CL, Ganguly T, Ganguly A (2014) Chromosome 3 status combined with BAP1 and EIF1AX mutation profiles are associated with metastasis in uveal melanoma. Invest Ophthalmol Vis Sci 55(8):5160-5167. https://doi.org/10.1167/ iovs.14-14550

56. Harbour JW, Roberson EDO, Anbunathan H, Onken MD, Worley LA, Bowcock AM (2013) Recurrent mutations at codon 625 of the splicing factor SF3B1 in uveal melanoma. Nat Genet 45(2):133-135. https://doi.org/10.1038/ng.2523

57. Decatur CL, Ong E, Garg N, Anbunathan H, Bowcock AM, Field MG, Harbour JW (2016) Driver mutations in uveal melanoma: associations with gene expression profile and patient outcomes. JAMA Ophthalmol 134(7):728-733. https://doi.org/10.1001/ jamaophthalmol.2016.0903

58. Furney SJ, Pedersen M, Gentien D, Dumont AG, Rapinat A, Desjardins L, Turajlic S, Piperno-Neumann S, de la Grange P, Roman-Roman S, Stern MH, Marais R (2013) SF3B1 mutations are associated with alternative splicing in uveal melanoma. Cancer Discov 3(10):1122-1129. https://doi.org/10.1158/2159-8290. CD-13-0330

59. Bonnal S, Vigevani L, Valcarcel J (2012) The spliceosome as a target of novel antitumour drugs. Nat Rev Drug Discov 11(11):847-859. https://doi.org/10.1038/nrd3823

60. Moore AR, Ceraudo E, Sher JJ, Guan Y, Shoushtari AN, Chang MT, Zhang JQ, Walczak EG, Kazmi MA, Taylor BS, Huber T, Chi P, Sakmar TP, Chen Y (2016) Recurrent activating mutations of G-protein-coupled receptor CYSLTR2 in uveal melanoma. Nat Genet 48(6):675-680. https://doi.org/10.1038/ng.3549 
61. Johansson P, Aoude LG, Wadt K, Glasson WJ, Warrier SK, Hewitt AW, Kiilgaard JF, Heegaard S, Isaacs T, Franchina M, Ingvar C, Vermeulen T, Whitehead KJ, Schmidt CW, Palmer JM, Symmons J, Gerdes AM, Jonsson G, Hayward NK (2016) Deep sequencing of uveal melanoma identifies a recurrent mutation in PLCB4. Oncotarget 7(4):4624-4631. https://doi.org/10.18632/ oncotarget.6614

62. Weis E, Shah CP, Lajous M, Shields JA, Shields CL (2006) The association between host susceptibility factors and uveal melanoma-a meta-analysis. Arch Ophthalmol 124(1):54-60. https ://doi.org/10.1001/archopht.124.1.54

63. Rishi P, Koundanya VV, Shields CL (2015) Using risk factors for detection and prognostication of uveal melanoma. Indian $\mathrm{J}$ Ophthalmol 63(2):110-116

64. Shah CP, Weis E, Lajous M, Shields JA, Shields CL (2005) Intermittent and chronic ultraviolet light exposure and uveal melanoma: a meta-analysis. Ophthalmology 112(9):1599-1607

65. Mainster MA, Turner PL (2010) Ultraviolet-B phototoxicity and hypothetical photomelanomagenesis: intraocular and crystalline lens photoprotection. Am J Ophthalmol 149(4):543-549

66. Purohit BS, Vargas MI, Ailianou A, Merlini L, Poletti P-A, Platon A, Delattre BM, Rager O, Burkhardt K, Becker M (2016) Orbital tumours and tumour-like lesions: exploring the armamentarium of multiparametric imaging. Insights Imaging 7(1):43-68

67. Shields CL, Cater J, Shields JA, Singh AD, Santos MC, Carvalho C (2000) Combination of clinical factors predictive of growth of small choroidal melanocytic tumors. Arch Ophthalmol 118(3):360-364

68. Makitie T, Summanen P, Tarkkanen A, Kivela T (2001) Tumor-infiltrating macrophages (CD68(+) cells) and prognosis in malignant uveal melanoma. Invest Ophthalmol Vis Sci 42(7):1414-1421

69. Pinzani P, Mazzini C, Salvianti F, Massi D, Grifoni R, Paoletti C, Ucci F, Molinara E, Orlando C, Pazzagli M, Neri B (2010) Tyrosinase mRNA levels in the blood of uveal melanoma patients: correlation with the number of circulating tumor cells and tumor progression. Melanoma Res 20(4):303-310. https:// doi.org/10.1097/CMR.0b013e32833906e3

70. el Filali M, Missotten GS, Maat W, Ly LV, Luyten GP, van der Velden PA, Jager MJ (2010) Regulation of VEGF-A in uveal melanoma. Invest Ophthalmol Vis Sci 51(5):2329-2337. https ://doi.org/10.1167/iovs.09-4739

71. Missotten GS, Notting IC, Schlingemann RO, Zijlmans HJ, Lau C, Eilers PH, Keunen JE, Jager MJ (2006) Vascular endothelial growth factor a in eyes with uveal melanoma. Arch Ophthalmol 124(10):1428-1434. https://doi.org/10.1001/archo pht.124.10.1428

72. Mallikarjuna K, Pushparaj V, Biswas J, Krishnakumar S (2007) Expression of epidermal growth factor receptor, ezrin, hepatocyte growth factor, and c-Met in uveal melanoma: an immunohistochemical study. Curr Eye Res 32(3):281-290. https://doi. org/10.1080/02713680601161220

73. All-Ericsson C, Girnita L, Seregard S, Bartolazzi A, Jager MJ, Larsson O (2002) Insulin-like growth factor-1 receptor in uveal melanoma: a predictor for metastatic disease and a potential therapeutic target. Invest Ophthalmol Vis Sci 43(1):1-8

74. Shields CL, Shields JA, Perez N, Singh AD, Cater J (2002) Primary transpupillary thermotherapy for small choroidal melanoma in 256 consecutive cases: outcomes and limitations. Ophthalmology 109(2):225-234

75. Wang Z, Nabhan M, Schild SE, Stafford SL, Petersen IA, Foote RL, Murad MH (2013) Charged particle radiation therapy for uveal melanoma: a systematic review and meta-analysis. Int $\mathrm{J}$ Radiat Oncol Biol Phys 86(1):18-26. https://doi.org/10.1016/j. ijrobp.2012.08.026
76. Gragoudas E, Li W, Goitein M, Lane AM, Munzenrider JE, Egan KM (2002) Evidence-based estimates of outcome in patients irradiated for intraocular melanoma. Arch Ophthalmol 120(12):1665-1671

77. Naseripour M, Jaberi R, Sedaghat A, Azma Z, Nojomi M, Falavarjani KG, Nazari H (2016) Ruthenium-106 brachytherapy for thick uveal melanoma: reappraisal of apex and base dose radiation and dose rate. J Contemp Brachyther 8(1):66-73

78. Weis E, Salopek TG, McKinnon JG, Larocque MP, TempleOberle C, Cheng T, McWhae J, Sloboda R, Shea-Budgell M (2016) Management of uveal melanoma: a consensus-based provincial clinical practice guideline. Curr Oncol 23(1):57-64

79. Bechrakis NE, Petousis V, Willerding G, Krause L, Wachtlin J, Stroux A, Foerster MH (2010) Ten-year results of transscleral resection of large uveal melanomas: local tumour control and metastatic rate. Br J Ophthalmol 94(4):460-466. https://doi. org/10.1136/bjo.2009.162487

80. Willerding GD, Cordini D, Moser L, Krause L, Foerster MH, Bechrakis NE (2016) Neoadjuvant proton beam irradiation followed by transscleral resection of uveal melanoma in 106 cases. Br J Ophthalmol 100(4):463-467. https://doi.org/10.1136/bjoph thalmol-2015-307095

81. Simpson ER, Gallie B, Laperrierre N, Beiki-Ardakani A, Kivelä T, Raivio V, Heikkonen J, Desjardins L, Dendale R, Mazal A, Bornfeld N, Sauerwein W, Flüehs D, Brualla L, Honavar SG, Reddy VA, Suzuki S, Murakami N, Saakyan S, Valskiy V, Amiryan A, Seregard S, All-Eriksson C, Hjelmqvist L, Lundell G, Sinclair G, Lundell M, Damato B, Errington RD, Mayles P, Mayles H, Bergstrom C, Grossniklaus H, Crocker I, Butker E, Wilson M, Haik B, Geischen H, Patra P, Duker J, Mignano J, Rivard M, Finger PT, Semenova E, Choi W, Kalach NI (2014) The American Brachytherapy Society consensus guidelines for plaque brachytherapy of uveal melanoma and retinoblastoma. Brachytherapy 13(1):1-14. https://doi.org/10.1016/j.brach y.2013.11.008

82. Pereira PR, Odashiro AN, Lim L-A, Miyamoto C, Blanco PL, Odashiro M, Maloney S, De Souza DF, Burnier MN Jr (2013) Current and emerging treatment options for uveal melanoma. Clin Ophthalmol 7:1669-1682

83. Seregard S, Pelayes DE, Singh AD (2013) Radiation therapy: uveal tumors. Dev Ophthalmol 52:36-57. https://doi. org/10.1159/000351055

84. Daftari IK, Char DH, Verhey LJ, Castro JR, Petti PL, Meecham WJ, Kroll S, Blakely EA (1997) Anterior segment sparing to reduce charged particle radiotherapy complications in uveal melanoma. Int J Radiat Oncol Biol Phys 39(5):997-1010

85. Damato B, Kacperek A, Chopra M, Campbell IR, Errington RD (2005) Proton beam radiotherapy of choroidal melanoma: the Liverpool-Clatterbridge experience. Int J Radiat Oncol Biol Phys 62(5):1405-1411. https://doi.org/10.1016/j.ijrobp.2005.01.016

86. Mishra KK, Daftari IK (2016) Proton therapy for the management of uveal melanoma and other ocular tumors. Chin Clin Oncol 5(4):50-57

87. Damato B, Kacperek A, Errington D, Heimann H (2013) Proton beam radiotherapy of uveal melanoma. Saudi J Ophthalmol 27(3):151-157

88. Sikuade MJ, Salvi S, Rundle PA, Errington DG, Kacperek A, Rennie IG (2015) Outcomes of treatment with stereotactic radiosurgery or proton beam therapy for choroidal melanoma. Eye (Lond) 29(9):1194-1198

89. Fakiris AJ, Lo SS, Henderson MA, Witt TC, Worth RM, Danis RP, Des Rosiers PM, Timmerman RD (2007) Gammaknife-based stereotactic radiosurgery for uveal melanoma. Stereotact Funct Neurosurg 85(2-3):106-112. https://doi. org/10.1159/000098525 
90. Seibel I, Cordini D, Hager A, Riechardt AI, Rehak M, Boker A, Bohmer D, Heufelder J, Joussen AM (2016) Cataract development in patients treated with proton beam therapy for uveal melanoma. Graefes Arch Clin Exp Ophthalmol 254(8):1625-1630. https://doi.org/10.1007/s00417-016-3356-4

91. Rundle P (2014) Treatment of posterior uveal melanoma with multi-dose photodynamic therapy. Br J Ophthalmol 98(4):494497. https://doi.org/10.1136/bjophthalmol-2013-304432

92. Campbell WG, Pejnovic TM (2012) Treatment of amelanotic choroidal melanoma with photodynamic therapy. Retina 32(7):1356-1362. https://doi.org/10.1097/IAE.10.1097/ IAE.0b013e 31822c28ec

93. Fagone P, Caltabiano R, Russo A, Lupo G, Anfuso CD, Basile MS, Longo A, Nicoletti F, De Pasquale R, Libra M, Reibaldi M (2017) Identification of novel chemotherapeutic strategies for metastatic uveal melanoma. Sci Rep 7:44564-44574. https://doi. org/10.1038/srep44564

94. Schmittel A, Schmidt-Hieber M, Martus P, Bechrakis NE, Schuster R, Siehl JM, Foerster MH, Thiel E, Keilholz U (2006) A randomized phase II trial of gemcitabine plus treosulfan versus treosulfan alone in patients with metastatic uveal melanoma. Ann Oncol 17(12):1826-1829. https://doi.org/10.1093/annonc/mdl30 9

95. Kummer M, Schuler-Thurner B (2017) Immunotherapy of uveal melanoma: vaccination against cancer. Methods Mol Biol 1499:273-278. https://doi.org/10.1007/978-1-4939-6481-9_17

96. Uveal melanoma (2016) National Institute of Health (https://clini caltrials.gov/)

97. Zimmer L, Vaubel J, Mohr P, Hauschild A, Utikal J, Simon J, Garbe C, Herbst R, Enk A, Kampgen E, Livingstone E, Bluhm L, Rompel R, Griewank KG, Fluck M, Schilling B, Schadendorf D (2015) Phase II DeCOG-study of ipilimumab in pretreated and treatment-naive patients with metastatic uveal melanoma. PLoS One 10(3):e0118564. https://doi.org/10.1371/journal.pone.01185 64

98. Piulats Rodriguez JM, De La Cruz Merino L, Espinosa E, Alonso Carrión L, Martin Algarra S, López-Castro R, Curiel García MT, Rodriguez Abreu D, Rullan Iriarte AJ, Berrocal Jaime A (2018) Phase II multicenter, single arm, open label study of Nivolumab in combination with Ipilimumab in untreated patients with metastatic uveal melanoma. Ann Oncol 29(suppl_8):viii442-viii466. https://doi.org/10.1093/annonc/mdy289

99. Agarwala S, Ross M, Zager J, Shirai K, Essner R, Smithers B, Atkinson VG, Sarson D, Wachter E (2018) Interim results of a phase $1 \mathrm{~b} / 2$ study of PV-10 and anti-PD-1 in advanced melanoma. In: MR congress 2018 abstracts. https://doi.org/10.1111/ pcmr. 12738

100. Sacco JJ, Nathan PD, Danson S, Lorigan P, Nicholson S, Ottensmeier C, Corrie P, Steven N, Goodman A, Larkin JMG, Evans TRJ, Kumar S, Coupland SE, Silcocks P, Marshall E (2013)
Sunitinib versus dacarbazine as first-line treatment in patients with metastatic uveal melanoma. J Clin Oncol 31(15):suppl. 9031

101. Gonsalves CF, Eschelman DJ, Thornburg B, Frangos A, Sato T (2015) Uveal melanoma metastatic to the liver: chemoembolization with 1,3-bis-(2-chloroethyl)-1-nitrosourea. AJR Am J Roentgenol 205(2):429-433. https://doi.org/10.2214/AJR.14.14001

102. Eschelman DJ, Gonsalves CF, Sato T (2013) Transhepatic therapies for metastatic uveal melanoma. Semin Intervent Radiol 30(1):39-48

103. Sato T (2010) Locoregional management of hepatic metastasis from primary uveal melanoma. Semin Oncol 37(2):127-138. https://doi.org/10.1053/j.seminoncol.2010.03.014

104. Parmiani G, Castelli C, Pilla L, Santinami M, Colombo MP, Rivoltini L (2007) Opposite immune functions of GM-CSF administered as vaccine adjuvant in cancer patients. Ann Oncol 18(2):226-232. https://doi.org/10.1093/annonc/mdl158

105. Gonsalves CF, Eschelman DJ, Sullivan KL, Anne PR, Doyle L, Sato T (2011) Radioembolization as salvage therapy for hepatic metastasis of uveal melanoma: a single-institution experience. AJR Am J Roentgenol 196(2):468-473. https://doi.org/10.2214/ AJR.10.4881

106. Ben-Shabat I, Hansson C, Eilard MS, Cahlin C, Rizell M, Lindnér P, Mattsson J, Bagge RO (2015) Isolated hepatic perfusion as a treatment for liver metastases of uveal melanoma. J Vis Exp 95:52490

107. de Leede EM, Burgmans MC, Martini CH, Tijl FGJ, van Erkel AR, Vuyk J, Kapiteijn E, Verhoef C, van de Velde CJH, Vahrmeijer AL (2016) Percutaneous hepatic perfusion (PHP) with melphalan as a treatment for unresectable metastases confined to the liver. J Vis Exp 113:53795

108. Chandran SS, Somerville RPT, Yang JC, Sherry RM, Klebanoff CA, Goff SL, Wunderlich JR, Danforth DN, Zlott D, Paria BC, Sabesan AC, Srivastava AK, Xi L, Pham TH, Raffeld M, White DE, Toomey MA, Rosenberg SA, Kammula US (2017) Treatment of metastatic uveal melanoma with adoptive transfer of tumour-infiltrating lymphocytes: a single-centre, two-stage, single-arm, phase 2 study. Lancet Oncol 18(6):792-802. https ://doi.org/10.1016/S1470-2045(17)30251-6

109. Sacco JJ, Kalirai H, Kenyani J, Figueiredo CR, Coulson JM, Coupland SE (2018) Recent breakthroughs in metastatic uveal melanoma: a cause for optimism? Future Oncol 14(14):1335-1338. https://doi.org/10.2217/fon-2018-0116

Publisher's Note Springer Nature remains neutral with regard to jurisdictional claims in published maps and institutional affiliations. 